\title{
TU/e EmonOWEN

\section{Applications of behavioural research on spatial problems II: preference and choice}

\section{Citation for published version (APA):}

Timmermans, H. J. P., \& Golledge, R. G. (1990). Applications of behavioural research on spatial problems II: preference and choice. Progress in Human Geography, 14(3), 311-354.

https://doi.org/10.1177/030913259001400301

DOI:

10.1177/030913259001400301

Document status and date:

Published: 01/01/1990

\section{Document Version:}

Publisher's PDF, also known as Version of Record (includes final page, issue and volume numbers)

\section{Please check the document version of this publication:}

- A submitted manuscript is the version of the article upon submission and before peer-review. There can be important differences between the submitted version and the official published version of record. People interested in the research are advised to contact the author for the final version of the publication, or visit the $\mathrm{DOI}$ to the publisher's website.

- The final author version and the galley proof are versions of the publication after peer review.

- The final published version features the final layout of the paper including the volume, issue and page numbers.

Link to publication

\section{General rights}

Copyright and moral rights for the publications made accessible in the public portal are retained by the authors and/or other copyright owners and it is a condition of accessing publications that users recognise and abide by the legal requirements associated with these rights.

- Users may download and print one copy of any publication from the public portal for the purpose of private study or research.

- You may not further distribute the material or use it for any profit-making activity or commercial gain

- You may freely distribute the URL identifying the publication in the public portal.

If the publication is distributed under the terms of Article 25fa of the Dutch Copyright Act, indicated by the "Taverne" license above, please follow below link for the End User Agreement:

www.tue.nl/taverne

Take down policy

If you believe that this document breaches copyright please contact us at:

openaccess@tue.nl

providing details and we will investigate your claim. 


\title{
Applications of behavioural research on spatial problems II: preference and choice
}

\author{
by Harry Timmermans and Reginald G. Golledge*
}

\section{Introduction}

The present article is the second of two articles that discuss examples of applications of behavioural research on spatial problems. The main objective of these review articles is to document the applied worth of behavioural geography. In particular, key ideas are explained and an attempt is made to demonstrate that over the years a unified body of knowledge and apparatus has been developed that can support applied decision-making problems in a variety of contexts such as urban and regional planning, transportation planning, architecture and urban design, marketing and so on. The first article discussed developments in the area of spatial cognition and assessment. In this sequel, advances in the field of preference, choice and decision making are reviewed.

The study of preferences and choice patterns is perhaps the most important contribution to date of behavioural geography to problems of an applied nature, because theories and models of preference and choice are widely used to forecast the likely impacts of policy decisions on spatial behaviour, and to assess the feasibility of envisaged projects. The traditional interest of geographers in spatial interaction patterns has led to a reformulation of the problem in new terms using behavioural theories and new model specifications. In addition, operational models have been developed for predicting the likely consequences of policy measures on spatial choice patterns. As a consequence of the growing popularity of this field of interest, many empirical applications occur in contexts such as migration, residential choice, shopping and recreation.

To understand the contribution of behavioural geography to the study of spatial interaction, it is important first to summarize the developments in this field since the mid-1960s. At that time aggregate models dominated the field. Gravity and entropy-maximizing models (Wilson, 1974) were not primarily concerned with

*Harry Timmermans is a Professor of Urban Planning at the Faculty of Architecture, Building and Planning, University of Technology, Eindhoven, The Netherlands. Reginald Golledge is a Professor of Geography at the Department of Geography. University of California at Santa Barbara. During the preparation of this paper. Professor Golledge was partially supported by a grant from the John Simon Guggenheim Foundation. 
individual choices but rather with interzonal orientation or interaction patterns which result from aggregating indjvidual choices across zones. Consequently, the parameters of gravity and entropy-maximizing models are highly influenced by the chosen zoning system, and it was this very property that generated considerable criticism of these aggregate models. It was argued that aggregate spatial interaction models merely describe observable interaction patterns rather than satisfactorily explaining them. The way was open for the development of a cognitive-behavioural approach seeking to understand the spatial decisionmaking process of individuals.

From the 1970s on, different types of behavioural choice models have been advanced. All of these are based on (variants) of a conceptual model that explicitly relates choice behaviour to the environment through consideration of perceptions, preference formation and decision making. It is assumed that individuals develop some cognitive representation of the real world. That is, in each decision-making task only a limited number of environmental characteristics are considered because individuals may not perceive all of the attributes. These characteristics are implicitly or explicitly evaluated and yield subjective impressions for the levels of the different choice alternatives in an individual's choice set. Limited knowledge of choice set characteristics may result in evaluation of only a subset of the available choice alternatives. Choices are assumed to be made on the basis of characteristics of this cognitive representation, rather than on characteristics of the environment itself. Individuals are assumed to attach some subjective utility to the attributes defining such a cognitive representation, and to combine these utilities into some overall utility according to some combination rule or decision heuristic. This results in a preference structure which defines the positioning of the choice alternatives in terms of overall utility or preference. Finally, it is assumed that such a preference structure is functionally related to choice behaviour. That is, the probability of choosing some alternative is assumed to be systematically related to the overall utilities of the choice alternatives included in an individual's choice set. Although most models have been concerned with problems of single choice behaviour, some attempts have been made to extend behavioural models of single choice behaviour to the case of trip chaining and activity patterns. Recently, the study of dynamic choice behaviour has become a growing concern. These three broad areas of research constitute the basis on which the remainder of this paper is organized.

\section{Models of single choice behaviour}

Perhaps the two most important lines of research in this area are related, respectively, to discrete choice models and decompositional multiattribute preference models. Other disciplines have also emphasized compositional and hybrid evaluation models. 


\section{Discrete choice models}

Conventional discrete choice models may be derived from at least two formal theories: Luce's strict utility theory (Luce, 1959) and Thurstone's random utility theory (Thurstone, 1927). Strict utility theory can best be considered as an extension of constant utility theory developed by psychologists to account for intransitivies in choice. In particular, Luce extended the weak and strong utility model for binary choices to the multiple alternative choice case. His theory assumes that the probability of choosing some alternative is equal to the ratio of the utility associated with that alternative to the sum of the utilities for all the alternatives in the choice set. Luce assumed deterministic preference structures and postulated a constant ratio decision rule.

In contrast, random utility theory was developed as a basis for measurement scales for comparative judgement, and assumes stochastic preferences in that an individual is assumed to draw at random a utility function at each choice occasion. At least, this is the interpretation given in the early psychological literature. The usual interpretation underlying current random utility models is that not all factors influencing choice processes are known to the analyst. Thus, an individual's utility for a choice alternative is assumed to consist of a deterministic component and a random utility component. In addition, random utility theory assumes a utility-maximizing decision rule which implies that the probability of choosing some choice alternative is equal to the probability that the utility associated with a particular choice alternative exceeds that of all other choice alternatives included in a choice set. The actual choice model then depends on the assumptions regarding the distributions of the random utility components. If it is assumed that the random utility components are independently and identically normal distributed with zero mean, the independent multivariate probit model results. If, however, it is assumed that these random components are independently, identically Type I extreme value distributed, the familiar multinomial logit model results. Anas (1983) found an algebraic equivalence between entropy-maximizing models and multinomial logit models. Evidently, this equivalence refers to the form of the model, not to the meaning of the equations.

Under strict utility theory, many different utility functions are allowed provided they are unique (except for multiplication by a positive constant). Under random utility theory many specifications are still possible, but for ease of estimation a deterministic utility component, linear in its parameters, is usually assumed.

The estimation of the parameters of discrete choice models typically involves establishing the functional relationship between the (evaluation of) the choice alternatives' attributes and overt choice behaviour. Several estimation techniques such as conditional logit analysis, weighted least squares. maximum likelihood and nonlinear least squares may be used. More recently, robust estimation techniques (see Wrigley and Dunn, 1984a; Dunn et al., 1984) and generalized linear models (O'Brien and Wrigley, 1984) have been suggested as viable 
alternatives. Adjusted likelihood functions and alternative estimates have been proposed for the case of choice-based sampling (e.g., Manski and Lerman, 1977).

Discrete choice models are perhaps the best-known models in spatial analysis. They have been applied in a variety of contexts such as residential choice behaviour (e.g., Onaka, 1983; Onaka and Clark, 1983; Van Lierop, 1981; 1985; Van Lierop and Nijkamp, 1984; Van Lierop and Rima, 1985; Longley, 1984; Veldhuisen, 1984; 1985), shopping behaviour and retailing (e.g., Southworth, 1981; Lerman and Liu, 1984; Miller and Lerman, 1981; Timmermans, 1984c), recreational choice behaviour (Peterson et al., 1983), in labour market studies (Fischer and Maier, 1984) and as models for the urban economy (Anas, 1982; 1984). In addition, closely related developments such as loglinear models and logit regression analysis are also well-known in geographical research (see Longley and Wrigley, 1984; Wrigley, 1985; Scholten and Hooimeyer, 1984; Willekens, 1983; Dieleman, 1983; Scholten, 1984; Willekens and Shah, 1984).

\section{Decompositional multiattribute preference models}

Decompositional multiattribute preference models are based on the assumption that individuals cognitively integrate their evaluations of a choice alternative's attributes to derive the utility for a choice alternative and arrive at a choice by selecting that alternative with the highest utility. Sometimes, discrete choice models are interpreted from the same perspective, although strictly speaking, utility-based models make no explicit assumptions about the mechanisms through which preferences are formed. They assume only that preferences satisfy conditions of transitivity, continuity and completeness. These conditions arc sufficient to ensure the existence of a utility function. An important difference between the two modelling approaches concerns data collection and parameter estimation. Unlike discrete choice models, the parameters of the decompositional multiattribute preference models are not derived from real-world data, but from experimental design data.

First, the attributes influencing the choice behaviour of interest are categorized. Next, these categories are combined according to the principles of some experimental design (full factorial, fractional factorial, or trade-off design) to yield a set of hypothetical choice alternatives. An individual is then requested to express some measure of preference for each choice alternative. These preference measures are then decomposed into the contributions of the categories of the attributes given some prespecified combination rule. Techniques like monotone regression analysis, analysis of variance or linear programming may be used for this purpose. Finally, the preference structure is linked to overt choice behaviour by specifying some decision rule. A more detailed account of the approach is provided in Timmermans (1984a).

Although decompositional multiattribute preference models are not explicitly derived from some formal theory, both strict and random utility theory may be linked with the approach. In addition, Anderson's information integration theory 
(Anderson, 1974) is associated with this approach. The theory asserts that a response is the result of the integration of information according to simple algebraic rules such as adding, averaging, subtracting and multiplying.

Whereas the nature of the combination rule has received relatively little attention in the context of discrete choice models, the testing of the most appropriate specification is an important step in decompositional multiattribute preference models. In particular, conjoint measurement and functional measurement have been used to test for the functional form of the utility expression. Both approaches attempt simultaneously to scale the stimulus attributes and response measures and to determine the compositional rule relating the two. Originally, conjoint measurement is an axiomatic approach. It is concerned with the conditions under which one can test for the adequacy of a combination rule to account for the observed ordering. In contrast, functional measurement is a numerical approach. For example, an additive combination rule is supported if the interaction terms in an analysis of variance tables are nonsignificant. Likewise, a multiplicative combination rule is supported by significant interactions, concentrated in multilinear terms. Usually, data plots are used to assist the analysis. A series of parallel lines indicate the existence of a linear rule, whereas a multiplicative rule is suggested by a series of converging/diverging lines. It should be noted that more recently both approaches have been used numerically. Now, conjoint analysis is most commonly associated with ordinal response scales, while functional measurement is normally associated with interval response scales.

Since decompositional multiattribute preference models primarily focus on the formation of preferences, most of these models have assumed a deterministic utility-maximizing decision rule. This assumes that the choice alternative with the highest preference score will be selected. More recently, however, different assumptions have led to more complicated specifications involving probabilistic decision rules (Louviere and Meyer, 1979; Timmermans and Van der Heijden, 1984).

Although decompositional models have been used in hundreds, if not thousands of studies, their practical application has been impeded by a number of unresolved problems and limitations. First, these models lack an integrated theoretical framework linking preferences to choice behaviour. Secondly, the form or parameters of utility or decision functions may vary with differences in choice set composition and therefore may not be context-independent. Thirdly, task demands for individual respondents become more and more onerous as the number of attributes and/or the number of levels of attributes increase. Fourthly, some combinations of attribute levels produced by experimental designs can result in the creation of unrealistic, hypothetical choice alternatives not encountered in the real world. Finally, it is difficult to predict the expected market shares of new choice alternatives in situations in which it is reasonable to expect competitive responses from existing alternatives. Recently, much progress has been made in providing possible solutions to these problems (see Louviere 
and Timmermans, 1987 for a more extensive discussion).

Louviere and Woodworth (1983) have suggested a methodology for simultaneous study of the process of preference formation and the choice process. Basically, their method amounts to estimating conventional random utility models using data on hypothetical choices. As with conventional decompositional models, their approach first involves identifying the attributes relevant to the decision problem and defining each of these attributes in terms of a series of attribute levels. Multiattribute choice alternatives are then generated by means of fractional factorial experimental designs in which each attribute is treated as a factor with varying numbers of levels. If the number of alternatives among which individuals will choose is constant (say $\mathrm{N}$ ), and each alternative has $\mathrm{M}$ attributes with L levels, one can construct choice sets that satisfy the MNL (or Luce's choice model, 1959; 1977) by designing an $\mathrm{LM} * \mathrm{~N}$ main effects, orthogonal, fractional factorial experimental design to create joint combinations of attribute levels. Next, sets of choice sets that are consistent statistically with MNL models are generated by using standard fractional factorial design techniques. These choice sets have a fixed number of alternatives, but the positions of these alternatives on the decision attributes vary from choice set to choice set. To establish the origin of the evaluation or utility scale, a constant choice alternative is added to each choice set. Individuals are requested to select one and only one alternative in each of several experimentally designed choice sets. Alternatively, individuals can be asked to estimate the proportion of their total patronage likely to be allocated to each alternative; or to allocate some fixed set of resources (e.g., dollars, points, trips etc.) to the available choices.

If the MNL choice model is approximately correct, a sufficient condition for estimating the part-worth values for the alternatives is that the independence of alternatives across choice sets be preserved. In practice, an orthogonal, fractional factorial, main effects design for varying the levels of the decision attributes will satisfy this condition. Likewise, the validity of the constant choice rule, underlying the MNL model can be tested by including the crosseffects of an alternative on another alternative in the utility arguments. An example of this approach is provided by Louviere and Hensher (1982). Louviere and Hensher developed a choice experiment to study choice of bus versus auto versus other modes for the journey to work. Three two-level attributes were varied to describe both the bus and auto mode. Fare, travel time and walking distance to bus stops were used for the bus, while gasoline costs per gallon, travel time and parking costs per hour were used for the auto. Each attribute was treated as a factor used to construct 16 different choice sets based on a $1 / 4$ fractional factorial design of the $2^{* *} 6$ full factorial. Respondents were asked to indicate which of the three alternatives they would be most likely to choose in each of the 16 choice sets. The results suggested that the respondents (college students) preferred buses to other modes, but were particularly sensitive to changes in bus attributes. Depending upon the statistical properties of the choice experiment, various parameters that represent the marginal or joint effects of each attribute of each 
alternative on the choice probabilities can be estimated.

The problem of varying choice set composition can be studied by extending the previously discussed Louviere and Woodworth (1983) approach. In this case, each of the multiattribute choice alternatives produced from the alternativegenerating' design is treated as separate two-level (present/absent) factors in a second, or 'choice set generating', design which is usually some fraction of a $2 \mathrm{~N}$ ( $\mathrm{N}$ is the number of total designed multiattribute alternatives created by the 'alternative-generating' design) factorial design. This second design is used to place alternatives into choice sets in such a way that the necessary and sufficient statistical conditions for estimating and testing the MNL choice model are satisfied. Fractions of $2 \mathrm{~N}$ designs produce choice sets that vary in size and composition. Generalized MNL models or any subsets thereof can be estimated from appropriately specified designs by means of maximum-likelihood or weighted-regression analysis. An example of a varying choice set size and composition problem is provided by Louviere and Hensher (1982) and Timmermans and Borgers (1985). Louviere and Hensher studied the problem of the choice of fast-food restaurants. Five major fast-food restaurant chains were used as the choice alternatives. Each of these could be present or absent, implying that 25 possible sets of choice sets are available. Eight of these possibilities were selected according to an orthogonal main effects fraction. In a similar vein, Timmermans and Borgers studied the problem of the choice of shopping centre.

A possible solution to the information overload problem has been suggested by Louviere (1984a). This so-called hierarchical information integration method is based on the hypothesis that, for many complex decision problems involving many influential attributes, individuals group attributes into sets. Each set defines a separate, higher-order decision construct, and individuals use rules to integrate attributes into decision constructs and decision constructs into overall evaluations and choices. The idea behind hierarchical information integration is to hierarchically structure conjoint tasks. This involves a clustering of the attributes into a fixed number of sets, each of which represents a different, high-order decision construct. Separate experimental designs are then developed for each of these sets to produce alternatives with multiple attributes. In addition, each of the higher-order decision constructs is treated as a factor whose levels are various categories from the rating scales used to define the constructs. The measurements and analyses are similar to those employed in conventional decompositional models. Finally, the separate statistical models that define each higher-order construct can be concatenated with the overall model if it is assumed that each separate decision process has an error distribution with a zero expectation and which is uncorrelated with any of the error distributions of the other decision processes. Louviere and Gaeth (1987) provide an example of this approach applied to an analysis of supermarket shopping behaviour. An application to the problem of recreational choice behaviour can be found in Louviere and Timmermans (1989). They selected 22 attributes influencing recreational choice behaviour. These attributes were then grouped into four higher-order decision 
constructs: natural environment and accessibility, things to do, maintenance and social use. For each of these constructs, a separate fractional factorial design was constructed to vary the levels of the attributes underlying the higher-order construct. In addition, an overall design was developed which consisted of descriptions of the four higher order constructs in terms of respondents' subjective ratings. Respondents were asked to evaluate one of the separate designs and the overall design on some rating scale. The results allow conclusions regarding the importance of the various attributes. Timmermans (1988) provides an example of this approach to the problem of housing choice. Respondents consisted of people who had just moved house in the Roermond region, The Netherlands. The influential attributes were clustered into four higher-order constructs: attributes related to the house, attributes relating to the residential environment, attributes related to the relative location of the house (vis-à-vis shopping centres, schools, bus stops, work etc.), and attributes related to the social and economic bonds of the respondents. Louviere's original method was further developed by introducing a choice design rather than a conjoint design in the measurement of the overall utilities. This allows one to study simultaneously preference formation and choice behaviour in hierarchical decision-making processes.

A practical problem associated with many decompositional preference models is that orthogonal experimental designs which are used to achieve estimation efficacy often produce infeasible or impossible choice alternatives. Recently, Louviere (1985) has suggested a potential solution to this problem that applies to a limited but important set of multiattribute problems in which all of the attributes of interest are quantitative. The approach is based on difference-in-utility functions, and requires individuals to make comparative or 'difference' judgments about two or more alternatives. The idea behind difference-in-utility models is to develop an arbitrary 'base' alternative whose attributes have the correlation properties of interest; construct an orthogonal difference design in which the elements of an orthogonal (fractional) factorial design are differences between the levels of the 'base' attributes and the attribute levels of the nonbase alternatives; and implement the task as a comparative judgment task or a choice task.

The final problem, that of dealing with competitive environments, has also been addressed by Louviere (1984b). In his approach, first the set of specific, named existing competitors to be researched, as well as the new, named competitor(s) of interest are identified. Then, the possible competitive actions and reactions that are likely to be taken by the new and existing competitors have to be defined. These actions and reactions are treated as experimental factors, and orthogonal designs are used to develop combinations of changes (the levels of the factors). Sets of choice sets are then constructed in the usual ways.

The treatment combinations from the separate designs for each competitor are randomly assigned to choice sets without replacement (or with replacement if the designs have differing numbers of treatments). Again, the measurement 
procedures and estimation methods are identical to those used in conventional decompositional models, and this approach allows one to estimate the effects of different attribute levels under competitive circumstances.

Although decompositional multiattribute preference models have been used less frequently in geography than discrete choice models, applications can be found in a variety of spatial contexts such as residential preferences (e.g., Knight and Menchik, 1976; Louviere and Meyer, 1976; Louviere and Henley, 1977; Louviere, 1979; Veldhuisen and Timmermans, 1984), migration (e.g., Lieber, 1979), shopping behaviour (e.g., Louviere and Meyer, 1981; Recker and Schuler, 1981; Timmermans, 1980a; 1982; Timmermans $e$ t al., 1984), travel analysis (e.g., Louviere and Wilson, 1978; Hensher and Louviere, 1979; Louviere and Kocur, 1983b) and recreation (e.g., Lieber and Fesenmaier, 1984).

\section{Compositional multiattribute attitude models}

Compositional multiattribute attitude models have been very popular in social psychology, sociology and marketing science. Different theoretical constructs have been used in applied research. For example, Rosenberg's attitude model (e.g., Rosenberg, 1956), which belongs to the class of expectancy value models, has been very popular. Expectancy value models have been used to identify the factors influencing motivated behaviour. These models assume that the strength of a tendency to act depends on the expectancy that the act will be followed by a particular outcome (subjective probability, expectancy, perceived instrumentality) and some affected values of the outcome (value importance). Expectancy value theory assumes that the strength of a tendency to act is a monotonically increasing function of the sum of the products of expectancy and value across outcomes. Rosenberg's model assumes that attitudes are associated with a cognitive structure, which consists of beliefs about the potentialities of the object for obtaining or blocking the realization of valued states.

Another well-known theory underlying compositional multiattribute attitude models is Fishbein's behavioural intention theory (e.g., Fishbein, 1967), based on behaviour theory of mediated generalization. It states that an individual's attitude towards a certain object or behaviour is a function of the beliefs of the individual about that object or behaviour and the evaluated aspects of these beliefs. In addition, it assumes that overt behaviour is also influenced by normative beliefs and the motivation to comply with these norms.

The above models have led to a discussion in marketing science regarding the constructs that should be used to operationalize them. Some authors (e.g., Cohen et al., 1972) have explicitly measured the importances attached to a choice alternative's attributes and the subjective evaluation of these attributes. Hence, they have substituted importance for evaluation in the measurement of the value component. In addition, object dimensions rather than specific characteristics are used. Their model is known as the adequacy-importance model.

Although these models are based on different theoretical constructs, they have 
in common that their independent variables are separately and explicitly measured. Hence, they all belong to the class of self-explicated models. They are compositional in that overall evaluations or attitudes are calculated rather than being explicitly measured. Strictly speaking, these models are not choice models since they do not include an explicit decision rule. However, whenever these models have been applied to choice problems, it has been assumed invariably that an individual chooses that alternative with the highest overall evaluation or the most positive attitude. In terms of our classificatory dimensions, all these models assume deterministic preferences, a deterministic decision rule and "utilitymaximizing' behaviour.

As far as the nature of the combination rule is concerned, all the above models use a linear additive rule. Hence, some type of compensatory decision making is assumed, in the sense that a low score on some attribute may at least partially be compensated for by high scores on one or more of the remaining attributes. In other fields of application, different combination rules, such as multiplicative rules, have been used. Both weighted and unweighted rules are commonly used. Another important distinction in this respect is that the above weighted models all assume that belief discrimination is related to preference in the sense that 'more is better' (vector models). In contrast, ideal point models assume that preference is inversely related to some function of the distance of a choice alternative from an individual's ideal point (Coombs, 1964).

In addition to vector and ideal point models, so-called part-worth models may be distinguished. Unlike ideal point and vector models, they do not assume that the weighting function is defined on the attribute level but rather on the level of each category of an attribute.

Only a few applications of these models in spatial analysis exist. Timmermans (1980b) has compared the predictive ability of weighted and unweighted multiplicative and additive models in the context of consumer choice of shopping centres. More recently, Desbarats (1983) has used Fishbein's attitude theory in a study of migration.

\section{Hybrid evaluation models}

Hybrid models constitute an amalgamation of compositional and decompositional models. They have in common with the compositional models the fact that an individual's evaluations of the attribute levels characterizing the choice alternatives are separately and explicitly measured. However, the importance weights are not separately and explicitly measured, but are estimated by regression analysis. Here the overall evaluation of the choice alternatives constitutes the dependent variable, while the independent variables consist of the self-explicated evaluations of the various attributes of the choice alternatives.

At least three types of hybrid model may be distinguished. The type most commonly used in disciplines such as behavioural science and management science (see Huber, Sahney and Ford, 1969; Huber, Daneshgar and Ford, 1971: 
Huber, 1974) are the linear and multiplicative models. The latter model can be estimated by multiple regression analysis by taking the logarithm of both sides of the equation. Another model is the addilog model, suggested by Huber (1974). As the name of the model suggests, this model assumes that a subject's utility for some choice alternative may be represented by a function which adds the logarithms of the part-worth utility associated with the individual attributes of the alternative. The model was suggested on the basis of empirical evidence which demonstrated that an individual's perception of differences in physical attributes is proportional to the logarithm of the difference and not to distance itself. Finally, the models introduced by Einhorn $(1970 ; 1971)$ and Einhorn and Gonedes (1971) as compensatory approximations of noncompensatory rules should be mentioned.

A second type of hybrid model has been introduced in marketing by Green and his associates (Green et al., 1981). This approach was introduced in response to the problem of prohibitive time and effort associated with traditional decompositional multiattribute preference models whenever the number of attributes and/or attribute levels is large. Their approach simplifies the experimental task while retaining individual differences in preference functions. The approach typically involves the following steps. First, the attributes influencing the choice behaviour under study are identified and defined in terms of a series of attribute levels. Next, an individual is asked to rate the attribute levels on some desirability scale and he/she is also invited to rate the attributes themselves in terms of the importance he/she attaches to them when choosing an alternative. These measurements constitute the self-explicated part of the measurement task. In the second stage of the measurement, an individual is presented with a small number of full-profile descriptions of hypothetical choice alternatives which are typically drawn in a balanced way from a much larger master plan (usually a fractional factorial design). such that the main effects and a limited set of twoattribute interactions can be orthogonally estimated. An individual is requested to evaluate each of these profiles in terms of overall preference. Hence, the second phase of the measurement typically follows the decompositional approach.

The multiattribute utility function may then be estimated by several hybrid conjoint models. The simplest model assumes that each individual's ability function is the weighted sum of the individual's self-explicated importance weights times attribute level evaluations and a segment or aggregate conjoint model with main effects and selected interaction effects. The segments are formed by clustering the individuals on the basis of their self-explicated data. Most commonly, ordinary least-squares regression analysis is used to fit the parameter values either simultaneously or by a stagewise procedure.

The above model is known as the single b-weight full hybrid conjoint model since the model only includes overall self-explicated utility values. The models may however be disaggregated by estimating separate slope parameters for different attributes constituting the self-explicated utilities. The resulting model 
is known as the multiple b-weight model.

The third hybrid evaluation model was introduced by Cattin et al. (1983) in marketing science. Their approach involves both the self-explicated and the full-profile data as required to estimate traditional compositional and decompositional preference models, respectively. The parameters of this model are estimated by using a Bayesian procedure which uses both types of data. Hence, their approach aims at providing more reliable estimates of the parameters of an individual's utility function.

\section{Some recent advances}

Although most of these modelling approaches have been applied successfully to a variety of spatial problems, they have not escaped criticism. Most of the criticism has been formulated in connection with conventional discrete choice models (MNL models), but applies also to the other approaches. Each point of criticism has stimulated new lines of research which will be briefly summarized in the following section. Most of the models discussed so far implicitly assume that:

1) The utility of a choice alternative is independent from the attributes of other alternatives in the choice set (independence from irrelevant alternatives (IIA) property): this implies that the models are not able to account for substitution and dominance effects;

2) Choice behaviour is compensatory;

3) The parameters of the models are invariant with changes in the variation in attribute levels of the choice set;

4) The introduction of a new choice alternative can never increase the choice probabilities associated with cxisting alternatives:

5) Choice behaviour is not influenced by indifference between choice alternatives:

6) The relative location of choice alternatives does not influence their choice probabilities.

In recent years, various alternative models have been developed which attempt to relax one or more of these assumptions.

\section{Substitution effects}

The IIA property of the MNL model imposes the constraint that the ratio of choice probabilities for any two alternatives is invariant with respect to the existence or nonexistence of other choice alternatives. It is a consequence of the assumed distribution of the random component of the utility function. It implies that a new choice alternative will obtain a share by drawing from the existing alternatives in direct proportion to their utilities.

During the past 10 years many alternative discrete choice models which can be subsumed under three general subclasses have been formulated to avoid this property. First, some models avoid the IIA property by relaxing the assumption of identically and independently distributed random utility components; some models allow for different variances of the error terms; others allow for positive 
correlations between error terms; still others allow for both. Secondly, another subclass of non-IIA models circumvents the IIA property by extending the utility specification to account explicitly for similarity between choice alternatives. Finally, a third group of non-IIA models assume a hierarchical or sequential decision-making process.

\section{Substitution models which impose more general conditions on the variance-covariance matrix}

Models belonging to this subclass differ in terms of their assumptions regarding the type of distribution of the error terms (negative exponential distribution, extreme value distribution and normal distribution), and assumptions on the error terms ((in)dependently/(not) identically or general variance-covariance structure and taste variation). In general, increasing the error variance of a choice alternative implies that the probability of choosing that alternative increases, even if the deterministic part of the utility function is equal to that of other alternatives. Likewise, the effect of introducing covariances between the error terms of two alternatives is that, ceteris paribus, they draw more share from each other.

Daganzo (1979) introduced a negative exponential distribution model that allows for different variances among the error terms. The model assumes that the error terms follow an independent exponential distribution with mean zero and standard deviation. The generalized extreme value model, introduced by McFadden (1978), avoids the IIA property by allowing positive correlations among error terms, but still assumes constant variances. The general probit model avoids the IIA property by introducing a general variance-covariance matrix for the error terms. Hausman and Wise (1978) proposed a conditional probit model that circumvents the IIA property by allowing correlation among error terms and differences in variances. Their model can be considered as a special case of the generalized probit model in that it attempts to model the variance and covariances of the random components of the utility functions in terms of measured perceptions.

Yet another model has been suggested by Kamakura and Srivastava (1984). Their model is similar to Hausman and Wise's, in that the covariances between the error components are defined a priori. However, rather than assuming random taste variation to be the only source of interdependence among choice alternatives, they assume the covariances between choice alternatives to be a function of how similar these alternatives are perceived to be by an individual in terms of the selected attributes.

\section{Substitution models with an extended logit formula}

The second subclass of non-IIA models share the property that substitution effects are incorporated by explicit consideration of the degree of similarity between the choice alternatives. Gaudry and Dagenais (1979) introduced the logit 
model into transportation science literature. Substitution or similarity effects are incorporated by means of alternative-specific parameters. In contrast, Batsell (1981) suggested incorporating such effects explicitly by adding a scale value that is related to the differences in attribute scores between choice alternatives. One of his models explicitly includes the objective characteristics of the choice alternatives; in a second model a set of parameters for substitution effects is empirically derived.

Two other models are very similar in spirit to the Batsell model. Geographers Meyer and Eagle $(1981 ; 1982)$ suggested capturing substitution effects not by introducing attribute-specific substitution parameters as in the Batsell case, but rather by defining a single overall substitution measure. The model introduced by Borgers and Timmermans (1988) can be considered as a kind of mixture of the Batsell model and the Meyer-Eagle model, in that it attempts to combine the most positive features of these two models.

A completely different approach was adopted by Huber and his coworkers. Perhaps the most extreme of his models is the cumulative logit model (Huber, 1982). This model assumes that choice is deterministic and that the alternative chosen is the one closest to an ideal mixture which is assumed to be normally distributed. This is a strict substitutability model since incorporating a new choice alternative takes shares from adjacent alternatives only. The model takes its name from the assumption that the cumulative distribution of ideal mixtures can be approximated by a logistic cumulative density function.

Another more general model has been suggested by Huber and Sewall (1982). This introduces an extra term in the utility function which reflects some measure of average distance from a choice alternative to all other choice alternatives. They tested several possible operationalizations of this similarity measure. One alternative calculated correlations across subjects in the rank ordering of the choice alternatives. These were scaled as similarities using nonmetric multidimensional scaling. Attributes of the two most preferred choice alternatives were rated and then formed into a dissimilarity score by summing the absolute differences of the averaged attribute measures for each pair of choice alternatives.

Cooper and Nakanishi (1983) introduced a method to transform interval scale values into positive ratio scales. When applied to their multiplicative competitive interaction model, this method produces violations of the constant utility assumption of Luce's choice axiom.

\section{Substitution models with a hierarchical or sequential decision structure}

Perhaps the best-known model that can be represented by a hierarchical decision structure is the nested logit model, which is a special case of the generalized extreme value model. Like the multinomial logit model, this model assumes that an individual evaluates alternatives according to a utility function. In this sense, the nested logit model is still a random utility model. Unlike the multinomial logit model, the alternatives which are supposed to be correlated are grouped into 
nests. Each nest is represented by an aggregate alternative with a composite utility consisting of the so-called inclusive value and a parameter to be estimated. To be correctly specified, the inclusive values should lie in the range between 0 and 1 , and the values of the parameters should change from lower levels to higher levels of the hierarchy (McFadden, 1978).

The nested logit model has received considerable attention in geography and related disciplines. Examples include McFadden (1978), Hensher (1983), Ortuzar (1983), Longley (1984), Fischer and Maier (1984) and Fischer and Aufhauser (1988).

Another model which avoids the IIA property is Tversky's elimination-byaspects model (Tversky, 1972a; 1972b). Each choice alternative is assumed to consist of a set of aspects. At each stage of the supposed sequential elimination process, an individual selects one aspect with a probability proportional to the importance of that aspect, and then eliminates all choice alternatives which do not possess that aspect. This process continues until a single choice alternative remains.

Some authors have attempted to parameterize Tversky's model. In a series of papers, Young (Young et al., 1982; Young and Ogden, 1983; Young and Brown, 1983; Young, 1984) has applied an elimination-by-aspects model in a variety of contexts, such as residential behaviour, road and rail freight mode choice and freight facility location choice. He assumed that individuals have a set of minimally acceptable satisfaction levels which are expressed as a fractional tolerance of the maximum satisfaction level for each attribute over all choice alternatives. This results in subsets of attributes which are satisfactory either for each choice alternative alone, or for combinations of choice alternatives. The probability of choosing an alternative is then based on attribute importances and choice alternative-specific constants which reflect unspecified satisfactory attributes. Young explicitly measured the importances in some of these applications, while in others they were calibrated. Also, the assumption of constant tolerances across subjects (adopted in his early applications) was later relaxed by allowing a distribution of tolerances (Young, 1984). Another model based on Tversky's ideas has been developed by Smith and Slater (1981) in a study of US interstate labour flows.

Two special cases of the elimination by aspects model are the hierarchical elimination model introduced by Tversky and Sattath (1979) and the hierarchical balance model suggested by Hauser and Tversky (1981). In the hierarchical elimination case, the elimination is not based on stochastic aspect selection, but on a fixed hierarchy of aspects. The model assumes that the probability of choosing an alternative is the product of the probabilities of selecting an aspect, which holds for that alternative at each step in the elimination process. Further it assumes that the probability of selecting an aspect is proportional to its overall weight. Like the hierarchical elimination model, the hierarchical balance model specifies choice among partitions. However, while the hierarchical elimination model assumes that the probability of selecting a choice set is proportional to the 
sum of the measures of all aspects which are associated with at least one alternative in the choice set, excluding shared aspects, the hierarchical balance model assumes that the choice probability is proportional to the sum of the aspect measures of each alternative in the partition, excluding shared aspects. Thus, while the hierarchical elimination model assumes that an individual only considers unique aspects, the hierarchical balance model considers an aspect even if only one alternative in a set does not contain that aspect.

Tversky's elimination by aspects model is able to encompass choice behaviour processes under conditions of similarity between choice alternatives. However, it does so by discarding the notion of an underlying utility scale. Strauss (1981) therefore suggested a choice by feature model, which does not share this disadvantage. The model supposes a Luce model independently for each feature and assumes that the alternative chosen is that where utility with respect to one of the features is at the overall maximum.

\section{Weight-shifting effects}

Conventional choice models typically assume that the model parameters are invariant with changes in the variation in attribute levels of the choice set. Considerable experimental work has demonstrated that the degree of variability existing among choice alternatives in the choice set on a particular attribute influences the choice process. It has been found that the larger the degree of variability, the more important the attribute becomes in the choice process (Eagle, 1984; 1988). This implies that the weight attached to a particular attribute shifts to those attributes with the higher degrees of variability.

Meyer and Eagle $(1981 ; 1982)$ developed a model which accounts for such weight-shifting effects. The model assumes that choice probabilities are not only related to differences in attribute values but also to linear-by-linear interactions between attribute differences and the absolute values of this difference on each remaining attribute. Unfortunately, to date no empirical studies have been conducted which attempt to compare the predictive ability of this weight-shifting model to that associated with other choice models.

\section{Prominence effects}

All models discussed so far exhibit the property that the introduction of new alternatives in a choice set will never increase the choice probability of any existing choice alternative. Yet, the introduction of new alternatives might cause an existing choice alternative to become more or less prominent, implying that the choice probability for this alternative may change. Yu (1978) and Smith and Yu (1982) developed a series of prominence models to account for such effects. An extra term representing the prominence of a choice alternative was included in the utility expression of the choice model. 


\section{Attraction and edge aversion effects}

An attraction effect is the tendency that the introduction of a new choice alternative in a choice set draws choices to alternatives similar to itself (Huber, Payne and Puto, 1982; Huber and Puto, 1983). It implies that the choice probability of an existing alternative might actually increase if a similar, but dominated or relatively inferior, alternative is added to the choice set. Huber (1982) proposed a modified Luce model which captures such effects. He incorporated two additional variables into the utility function which reflect a directional shift in the utility due to adding moderate or extreme choice alternatives.

In a series of experiments, Huber, Payne and Puto (1982) found that individuals show a tendency to avoid choosing alternatives that have extreme scores on particular attributes. This effect has been called an edge aversion effect. Huber (1982) has modelled this effect in a rather heuristic fashion and a specific context similar to his approach towards incorporating attraction effects in the utility function.

\section{Threshold effects}

Conventional discrete choice models do not allow indifferences between choice alternatives, although much psychological research has suggested that individuals are indifferent between choice alternatives if their difference in utility is small. Therefore, a few attempts have been made to incorporate threshold effects into discrete choice models.

Krishnan (1977) introduced a model that incorporates thresholds of indifference into the binary logit model. The model states that an alternative will be preferred only if its utility is greater than that of the other alternative plus some threshold value. The model was applied in the context of mode choice behaviour. Lioukas (1984) has extended this model to the multiple alternative case.

\section{Spatial competition and agglomeration effects}

Almost all spatial choice models are based on the assumption of independence of the spatial structure. The parameters of these models are not influenced by the arrangement of the alternatives in the study area. The models fail to account for competition and agglomeration effects.

Recently, Fotheringham (1983a; 1983b; 1984; 1985) suggested modifying traditional spatial interaction models to correct this type of mis-specification. Basically, he included an extra variable, which represents the accessibility of a destination to all other possible destinations. This accessibility term is raised to a certain power. If this parameter is positive, then agglomeration effects are dominant. If the parameter for the accessibility variable is negative, then competitive forces between destinations are dominant. Following Fotheringham's 
general ideas, Borgers and Timmermans (1988) have shown that agglomeration and competition effects can also be included in discrete choice models.

\section{Effects of noncompensatory decision making}

Most of the preceding models assume a compensatory decision-making process, in that they allow a low score on some attribute to be at least partially compensated by high scores on one or more of the remaining attributes. Only some of the hierarchical models do not share this feature. Over the years a series of noncompensatory decision and choice models have been formulated based on the assumption that individuals adopt noncompensatory decision strategies. That is, they assume that individuals screen choice alternatives on an attribute-byattribute basis when arriving at a choice or decision.

Johnson and Meyer (1984) have examined whether changes in the structure of a contingent choice process affect the parameters and fit of a compensatory model. They developed a theoretical, so-called 'stochastic' elimination model which assumes that individual choice processes consist of a series of elimination stages. At each stage an individual defines an elimination policy which reduces the set of candidate choice alternatives. They also assume that the probability that an alternative will belong to a candidate set at each stage equals the probability that the utility of a choice alternative exceeds some stochastic threshold value. By assuming that these random variables for each alternative have independent identically distributed logistic densities, it follows that under the assumption of independent probabilities of candidate set membership, the probability of choosing an alternative can be algebraically determined.

The Johnson-Meyer model is a parametric model. Models using nonparametric decision rules also exist. These describe noncompensatory decision-making processes. (See Timmermans, 1984b for a detailed review and axiomatization; see also Montgomery and Svenson, 1976; Svenson, 1979.) One of the rules is the conjunctive decision rule which states that a choice alternative will only be chosen if it meets a set of criteria defined on the attributes, implying that the least satisfactory attribute value of a choice alternative is critical to its acceptance. In contrast, the disjunctive decision rule assumes that an alternative will be chosen if it has at least one attribute greater than the corresponding criterion. The lexicographic decision rule assumes sequential decision making. Alternatives are compared on the most important attribute first. If one of the alternatives has uniquely the highest score on this attribute, it will be chosen. If, however, two or more choice alternatives are equally attractive on the most important attribute, they are compared on the second most important attribute. This process continues until a single alternative remains, or until all attributes are considered. Two more general rules are the lexicographic semi-order rule and the minimum difference lexicographic rule which have the additional assumption that there is a minimum difference, defined for the most important attribute, respectively, for all attributes and that the next attribute will be used to screen the choice 
alternatives only when the difference between alternatives is less than the minimum/minima.

Unfortunately, few studies have examined the predictive validity of these rules. Foerster (1979) has tested some of these rules in the context of transportation science, while Timmermans (1983) has tested whether some of the noncompensatory rules can reproduce overt shopping choice behaviour. He found that their predictive ability was significantly less than that of compensatory decision rules. In both of these studies, the authors tested whether there exists some rule which can predict actual choice behaviour. Other more recent studies considering such noncompensatory rules have been conducted by Phipps and Laverty (1983), Phipps and Meyer (1985) and Hendriks (1985). All these examine problems of residential choice behaviour. Other authors (Gensch and Svenstka, 1979; Recker and Golob, 1979), have examined the set of minimum differences, the main difference between these two studies being the way in which parameters are derived.

It is evident that when using such decision rules, the interest shifts from parameterized models of choice behaviour and human decision making to process tracing. The approach is closely related to information-processing theory and human problem solving (discussed earlier), in which the dynamic process by which a decision maker seeks and evaluates information sequentially is addressed. Two important developments related to this line of inquiry are decision net/ decision plan methodology and the computational process models. Basically, decision nets and decision plans involve portraying, at a very detailed level, an individual's decision-making process. Decision plans incorporate in addition the goal hierarchy of all problem-solving strategies ranging from problem recognition to actual behaviour, whereas a decision net is restricted to evaluating choice alternatives and choice. In constructing such nets an individual is first asked to name the attributes that are sequentially considered in the process of choice behaviour (i.e., in evaluating choice alternatives). Once this task is completed he/she is asked whether a choice alternative would be rejected or still considered when an attribute is not satisfactory. If a choice alternative is still considered, the researcher tries to identify under what conditions the alternative will be accepted. For example, the alternative may be accepted when all the remaining attributes are satisfactory, or if other attributes compensate for the unsatisfactory level of the attribute. Given these answers, the set of acceptable choice alternatives may be constructed and an individual's preference for each alternative within this set may be measured. The predictive ability of a decision net may be tested by describing the choice alternative in terms of its attribute level and then searching along the net to see whether the alternative is acceptable. Of course, this will not necessarily lead to a unique choice. To date few applications of this methodology to spatial problems exist (Timmermans and van der Heijden, 1987; Op't Veld et al., 1987), but results obtained so far in disciplines such as management science, marketing science, psychology and anthropology (e.g., Bettman, 1970; Miller et al., 1960; Swinth, 1976; Park et al., 1981) indicate this could be a very promising line of development. 
In criticism to this approach, some authors have doubted whether individuals are capable of articulating such plans since they have little awareness of the nature or even the existence of the cognitive process that mediates judgemental inferences and predictions of complex behaviour. However, it is evident that the approach has the potential of describing the nature of the decision-making process, including the effects of situational factors and contingencies in a detailed manner. Especially if the aim of the research project is to gain insight into the decision-making process itself, it might be a valuable approach.

Computational process models have their roots in information processing, cognitive psychology and artificial intelligence. The basic idea is that decisionmaking processes can be formalized as computer programmes and hence special computer languages such as PROLOG and LISP have been adopted for this approach. The primary concern of the approach is to identify what types of information exist, how this information is coded and organized, by what mechanisms it is activated and spread, and what cognitive processes act upon the knowledge structure to generate behaviour.

The knowledge structure is supposed to consist of declarative knowledge and procedural knowledge (if-then productions). Processes such as activation spread and pattern matching have been suggested as processes by which the knowledge structure is accessed and modified. A distinction between a short-term memory (the activated part of the knowledge structure) and a long-term memory is important in this respect. All these elements are organized into a cognitive architecture which determines the sequence of information processing.

One such architecture is the production system. It represents a list of productions (IF $<$ condition $>$ THEN $<$ action $>$ ). A production system essentially consists of a set of independent productions which are stored in long-term memory, a short-term memory that is composed of a small number of symbol structures, a set of pattern-matching rules which compare the condition sides of the productions with the short-term memory, and a set of conflict-resolution rules which determine which of the activated productions will be executed.

Computational process models were introduced in geography by Smith, Pellegrino and Golledge (1982) and Smith (1983). Smith and Lundberg (1984) showed that these models were capable of incorporating a variety of decision heuristics. In the context of actual decision making, an important issue is concerned with obtaining the minimal set of production rules that predict conditions under which an action is generated and the sequence in which such actions are made during a decision-making task. Smith, Clark and Cotton (1984) describe a procedure for finding this minimal set. Observed behaviour is represented by a sequence of state-action pairs. An individual's state can be represented by a conjunction of values over a set of variables, and hence a stateaction pair may be described by a set of disjunctions or conjunctions. For each action a set of disjunctions or conjunctions of such pairs may be identified. An action may be predicted by comparing the state of the system with various conditions of the production rule, and selecting the best match. 
Smith and his colleagues select the minimal set by adding one condition at a time in a sequential fashion in such a way as to increment maximally a criterion function. They found that such rules were highly predictive of sequences of actions in a simulated housing market search task. In a follow-up study, Clark and Smith (1985) provided some evidence that the production rules derived from experimental tasks were also consistently related to actual real-world behaviour. Another interesting study in this area of housing search is that by Johnson and Payne (1985).

\section{Trip chaining and activity patterns}

Conventional choice theory has been criticized in that no explicit consideration of multistop-multipurpose behaviour is given (see e.g., Hanson, 1980). Choice theory is usually based on axioms of single choice, single purpose trips, independence, separability and stable utility functions. Conventional disaggregate choice models assume that individuals choose only one alternative within any functional class, and only one at a time. Choices are assumed to be independent, while the utility associated with a choice alternative is not affected by the utility of any other choice alternative. Finally, any systematic variation in utility is denied. In recent years, this type of criticism has led to the development of models of trip chaining and activity patterns and to much empirical work designed to test, either explicitly or implicitly, the assumptions underlying discrete choice theory.

The study of trip chaining in itself was not new. Early studies developed around 1960 (Hanson, 1979), but both methods and applications have become more versatile and more complex. Part of this research effort involves empirical analyses of trip chaining and activity patterns. Some authors have investigated the linkages between work trips and nonwork trips (e.g., Oster, 1979; Hanson, 1980; Damm, 1982; Adiv, 1983; Kondo and Kitamura, 1987). Others have examined the spatial and temporal characteristics of trip chaining (e.g., O'Kelly and Miller, 1984; Kitamura, 1983; Golob, 1984; 1986; Nishii and Sasaki, 1986; Hanson and Hanson, 1981). Perhaps the most important advances, however, have been made in the area of modelling trip chaining and activity patterns.

At least three general approaches to modelling trip chaining behaviour and activity patterns may be distinguished. First are those using Markov theory. Second is the generalization of conventional discrete choice theory to account for trip-chaining behaviour. Finally, simulation models have been developed to describe and explain trip chaining and activity patterns.

\section{Markov chains}

The problem of trip chaining and multipurpose trips has traditionally been studied by Markov chain models. These models are based on a transition probability 
matrix which describes the probability that a particular destination $j$ will be chosen given that the previous stop was at destination $i$. These transition probabilities are derived from observed choice patterns. The advantage of these models lies in their ability to derive some general aspects of trip-chaining behaviour by manipulating the transition probability matrix. For example, the probability that some choice alternative will be chosen in a given number of steps can be calculated by raising the matrix to a power equal to the number of steps. Likewise, the accessibility of the choice alternatives and the overall choice probabilities can be calculated by simple matrix operations. Examples of Markov chain models for this type of analysis are presented by Marble (1964), Horton and Schuldiner (1967) and Wheeler (1972).

Despite the positive features of conventional Markov chain models, their applicability is limited by a series of rigourous assumptions. First, Markov chains are based on the assumption that the transition probabilities are independent from previous stops (history independence). Secondly, they are based on strong homogeneity assumptions regarding the trip-chaining behaviour of individuals. Thirdly, they are based on the assumption of stationarity which implies that the transition probabilities do not vary over time regardless of the number of stops made in the past. Finally, they do not offer an explanation of trip-chaining behaviour.

To relax these rigourous assumptions, more sophisticated Markov models, mostly based on Markov renewal theory and the theory of semi-Markov processes, have been developed (e.g., Gilbert et al., 1972; Kitamura and Lam, 1983). Kitamura (1983) tackled the problem of history dependence by modelling trip purpose linkages as a history-independent Markov chain process in which combinations of trip purposes were treated as separate states of the chain. Perhaps the most general of such models is the time-variant Markov chain model, suggested by O'Kelly (1981), which places trip-chaining behaviour explicitly in the context of multipurpose behaviour and the functional relationships between choice alternatives. Borgers and Timmermans (1986a) have attempted to overcome the problem of the deficiency of explanatory power of Markov chain models by assuming that trip chaining is a form of sequential decision making and that the choice of a destination at each step of this decision-making sequence is based on a deterministic preference structure and Luce's choice axiom.

\section{Developments based on discrete choice theory}

Over the years, a number of researchers have employed or elaborated discrete choice theory to derive models of trip-chaining behaviour and travel patterns. Perhaps the most straightforward of these is a model proposed by Adler and BenAkiva (1979). They used a standard multinomial logit model to predict travel patterns. A travel pattern was defined as a combination of tour frequency, sojourn frequency, mode of travel, and location of destination. Scheduling convenience of the arrangement of sojourns and tours, net nonhome activity 
duration, remaining income after travel expenses, attributes of the destinations and socioeconomic characteristics of the household were selected as factors influencing travel pattern choice. It is evident that this model involves an enormous choice set, but it is not necessary to enumerate the complete set in order to obtain consistent estimates for the logit model. The model performed well. However, as Horowitz (1980) has argued, this model provides no means for distinguishing actually considered travel patterns from those principally available. Nor does it address the statistical and computational issues associated with enumerating large sets of closely related alternative travel patterns.

In order to surmount these problems, Horowitz (1979) developed a utilitymaximizing model of the demand for nonwork tours. The model considers travel frequency, destination choice and multidestination travel, which are computed as functions of household characteristics, destination characteristics and transportation level of service.

A disadvantage of this model is that it does not treat mode choice and it contains no representation of the demand for travel between individual origindestination pairs. In order to overcome this, Horowitz (1980) developed a second utility-maximizing model of the demand for multidestination nonwork travel. His general theory can be reduced to a set of logit models for nonwork mode and destination choice if trip frequencies are known.

Most of the above models assume that daily activity patterns and trip chaining can be modelled by assuming that the underlying decision process is simultaneous. An alternative approach is to adopt an approach that assumes that decisions are sequentially made. Examples of sequential models can be found in van der Hoorn (1983a; 1983b) and Kitamura and Kermanshah (1983; 1984). Also, the nested logit model has been suggested as a possible solution to accommodate sequential structures in trip chaining behaviour. Another model has been suggested by Kitamura (1984a). He introduced the concept of 'prospective utility' that represents the expected utility of the visit to a choice alternative and also that of subsequent visits to other alternatives.

\section{Simulation models}

A third approach to the study of trip-chaining behaviour is that of simulating individual choice behaviour. Compared to both previous approaches, simulation approaches are relatively flexible, in the sense that a wide variety of rules which guide the simulation may be used. However, strictly speaking, simulation models usually lack explicit preference and choice rules and hence cannot be considered as theoretical choice models.

Many of these models stem from time geography. For example, Westelius (1973) developed a simulation model based on the assumption that a combination of purposes during a trip is a function of needs that coincide in time and the relative locations of activities. In addition, he makes a distinction between activities fixed in time and space and activities for which an individual has a 
choice. The needs may vary as a function of distance to choice alternatives and socioeconomic variables. For a given purpose and distance, a minimum need is necessary to generate a trip. This threshold may be lowered as a result of a visit nearby. Actual trip behaviour is simulated on the basis of such rules.

Another example is Lenntorp's (1976) model which explicitly considers time and space constraints. Here the location of different functions and the transportation network are given. An activity programme defined in terms of origin, destination and duration is presupposed. The output of the model consists of the various possibilities for realizing the activity programme.

The above models are only two examples. Similar models have been suggested by Root and Recker (1983), Swiderski (1983); Huigen (1983), Kitamura (1984b), Borgers and Timmermans (1986b) and Koppelman and Pas (1985). Perhaps the most sophisticated system is a model system developed by Recker, et al. (1986a; 1986b) which has been called STARCHILD.

\section{Models of dynamic choice behaviour}

A final important research direction relates to the stationarity assumption underlying conventional choice models. Recently choice behaviour has been studied as a dynamic process, resulting in the formulation of dynamic choice models. The emphasis is on the dynamics of choice behaviour. Associated with this research direction is the use of panel data. Seminal work in this area was concerned with distinguishing between true state dependence and spurious state dependence resulting from serial correlation, but more recently the first applications have begun to emerge.

The present discussion will be restricted to three general types of modelling approaches: stochastic models of buying behaviour, variety-seeking models and dynamic discrete choice models. It should be noted that these models constitute only a small part of this rapidly growing field of research. Other, more detailed reviews can be found in Halperin and Gale (1984), Halperin (1985), Hensher and Wrigley (1984) and Timmermans and Borgers (1989).

\section{Stochastic models of buying behaviour}

Stochastic models of buying behaviour have received continuous attention from geographers ever since the late 1960 s. These models, originally developed in marketing to study the dynamics of brand choice behaviour, have been extended to study consumer choice of spatial alternatives such as stores and shopping centres. Two different types of models may be distinguished.

Brand choice models predict which choice alternative will be chosen given that a choice is made at a particular point in time. Purchase incidence models predict when an alternative will be chosen or how many alternatives will be chosen in a particular time interval. 


\section{Brand/store choice models}

Perhaps the most simple brand/store choice model is the Bernoulli model. It is based on the assumption that the probability of choosing alternative $i$ is constant over time, implying that the past history of the process has no effect on the choice probabilities. The model also assumes homogeneity: the choice probabilities are assumed to apply to all individuals. In a marketing context, these simple models have often worked well. An application in a spatial context, although less successful, is presented by Burnett (1975) in a study of spatial shopping behaviour using panel data.

To relax the homogeneity assumption, the compound beta Bernoulli model has been developed. The model still assumes that every individual in the population has a constant probability $p$ of choosing a given alternative and a probability of $(1-p)$ of choosing another alternative; however, the homogeneity assumption is replaced by assuming that $p$ has a beta distribution over individuals in the population.

Yet another modelling approach in the study of dynamic choice behaviour is the Markov model. It is a first-order model which assumes that choice probabilities are only influenced by the previous choice. Hence, a transition probability matrix which expresses the probability that alternative $j$ will be chosen at time $t+1$ given that alternative $i$ has been chosen at time $t$ is typically derived. Conventional Markov models also assume homogeneity and stationarity. Given these assumptions, choice behaviour and market shares at some future point (time $t^{*}$ ) can be calculated by raising the transition probability matrix to the power $t^{*}$ and multiplying this matrix by an initial state vector. Likewise, the vector of steady state probabilities can be calculated in a straightforward manner. Geographical applications of the Markov model can be found in Burnett (1974; 1978) and Crouchley et al. (1982).

More recently, several attempts have been made to relax the rigourous firstorder, homogeneity and stationarity assumptions on which the conventional Markov model is based. Higher-order Markov models have been developed to incorporate the effect of choice behaviour at times $t-1, t-2$, etc., on choice behaviour at time $t+1$. Nonstationary, time variant models have been proposed to make the transition probability matrix dependent upon the time period. Heterogeneity has been introduced by segmentation of the population into groups.

Models with a more specification parameterization are the brand/place loyalty model, the last purchase/place loyal model and the linear-learning model, but these models have found only limited application in spatial research (see Golledge, 1970; Burnett, 1977).

\section{Purchase incidence models}

Perhaps the best-known model belonging to this class of dynamic models is 
Ehrenberg's negative binomial model. His model assumes that the average number of purchases of a particular alternative is constant over time periods; that the purchases of an individual over successive equal-length time periods can be described by a Poisson distribution; and that the average purchase rates are distributed over individuals according to a gamma distribution. Under these assumptions, the aggregate distribution of purchase events is described by a negative binomial distribution. Other interesting measures, such as the incidence of repeat buying, average purchase frequency and market penetration can be derived in a straightforward manner (Ehrenberg, 1972).

The basic model has been extended in a number of important ways to relax its assumptions. Chatfield et al. (1966) have shown that the distribution of the total number of purchases in a fixed time interval for individuals who purchase the item at least once during the interval can be approximated by the logarithmic series distribution. Other distributions, such as the zero-truncated negative binomial (Zufryden, 1977) and the geometric model have been used. The implication of the Poisson distribution that the interpurchase times are exponentially distributed have been questioned and the Erlang 2 distribution has been introduced to describe supposedly more regular interpurchase times (Herniter, 1971; Jeuland et al., 1980).

The negative binomial model has been applied successfully in marketing science (see Ehrenberg, 1968; 1972) to brand choice behaviour. Wrigley (1980) was the first geographer to use this model in a study of purchasing patterns at particular store types. In a follow-up study, the model was successfully applied to purchasing at individual stores in Cardiff (see Wrigley and Dunn, 1984b; Dunn, Reader and Wrigley, 1983).

Another important development is the generalization of the model to the case of more brands or stores (Goodhardt et al., 1984). Their model assumes that individual's choice probabilities are constant over time and independent over successive purchases, implying that the number of purchases of each alternative an individual makes in a sequence of purchases can be modelled by a multinomial model; that these choice probabilities vary across individuals according to a Dirichlet distribution; that successive purchases by an individual are independent with a constant mean rate (implying that the number of purchases made in each of a succession of equal-length time periods follows a Poisson distribution); that the mean purchasing rates vary among individuals according to a gamma distribution of the choice probabilities; and that average purchase frequencies of different individuals are distributed independently over the population. The model is obtained by mixing these multinomial, Dirichlet, Poisson and Gamma distributions. The model has worked remarkably well in marketing science (Goodhardt et al., 1984) but also for predicting brand purchases within store groups (Kau and Ehrenberg, 1984) and multistore purchase patterns within individual stores (Wrigley and Dunn, 1984c; 1984d).

A similar model has been developed by Jeuland et al. (1980) but they replaced the Poisson distribution by the Erlang 2 distribution, which results in a multiple 
hypergeometric model. This model worked well in a study of purchases of cooking oil. Yet another model has been advanced by Zufryden (1977). His model is also based on the Erlang and Gamma distribution of purchase incidence and on the assumption of independence between choice behaviour and purchase incidence behaviour, but he uses a linear model with purchase probabilities varying over the population according to a beta distribution rather than a multinomial distribution. His model also performed extremely well (Zufryden, 1978).

None of the above models incorporate explanatory variables. Consequently, the effects of managerial or planning decisions on behaviour cannot be assessed. In order to circumvent this disadvantage a number of authors have proposed models which basically add explanatory variables to the models discussed in this section. For example, Jones and Zufryden (1980) proposed a logit model to explain brand choice probability as a function of purchase explanatory variables. Following Ehrenberg, they assume the negative binomial distribution to describe the product class purchase distribution over the population. The probability of choosing a particular alternative given that the class purchase is being made is then modelled in logit form. This assumes heterogeneity among individuals with respect to the choice probabilities (beta distribution), independence from past purchase outcomes, and time invariance. Examples of applications of this approach can be found in Jones and Zufryden (1980; 1982). In a similar vein, Paull (1978) used a polytomous logit regression approach to predict discrete purchase quantities in a generalized negative binomial distribution. Broom and Wrigley (1983) and Wrigley and Dunn (1985) have proposed incorporating explanatory variables into negative binomial and Dirichlet models using log linear forms. Such extensions clearly are an important step forward in building policyrelevant models of dynamic choice behaviour.

\section{Models of variety-seeking behaviour}

Conventional choice models assume that their parameters are stable over time. An alternative hypothesis would be that individuals seek variety in the short run when choosing among choice alternatives. Over the past decade a number of variety-seeking models have been developed. Some of these address the problem of structural variety (the variety that is present within a set of objects); others address the problem of temporal variety (the variety that is implied by a sequence of choices - Pessemier, 1985). An initial distinction should be made between two types of models: inventory-based models and noninventory-based models (Timmermans, 1985). The specification of the former type of model is explicitly based on the assumption that the attributes of the chosen alternatives are accumulated in attribute inventories, whereas the latter type of model is not explicitly parameterized in this respect. 


\section{Inventory-based variety-seeking models}

One of the first models of variety-seeking behaviour, originally developed for the case of structural variety, was proposed by McAlister (1979). This so-called model of attribute satiation was built from two basic assumptions: attributes are cumulative, implying that the total amount of a particular attribute inherent in a group can be calculated by summing the attribute values across the alternatives belonging to that group; and the marginal utility for each attribute is a function of the square of the difference between the summed attribute values and an individual's ideal point. In the same study, a more sophisticated version based on Farquhar and Rao's balance model (Farquhar and Rao, 1976) was tested. They divided the attributes into four types. First, they made a distinction between desirable and undesirable attributes. Their relationship to preference is assumed to be reflected in a linearly increasing, respectively, decreasing function. Secondly, they assume that preference for a collection of choice alternatives is also influenced by the diversity within the collection. If diversity increases preference the attribute is called 'counterbalancing'. If, in contrast, preference decreases with increasing diversity, the attribute is termed 'equibalancing'. For both these types of attributes, Farquhar and Rao posit a linear relationship with preference for the collection of choice alternatives.

In a follow-up paper, McAlister (1982) extended the attribute satiation model to the case of temporal variety seeking. This dynamic attribute satiation model (DAS) differs from its predecessor in that a time-related additional assumption is built in. It is assumed that a consumption history may be converted into an inventory by a time-related inventory retention factor. Later, McAlister and Pessemier (1982) extended the DAS model by a term which represents the stimulation contribution to preference.

Yet another model was suggested by Pessemier (1985). He assumed that change in utility results from each attribute of a choice alternative and from interpersonal and intrapersonal variety which the object conveys. An individual's utility for a choice alternative is assumed to be a linear function of the squared distance between the individual's ideal point and the inventory position of that choice alternative in a space of $\mathrm{K}+2$ dimensions. This space is made up of $\mathrm{K}$ dimensions associated with the attributes, 1 dimension associated with intrapersonal variety and 1 dimension wih inteipersonal varicty. Definition of the inventories depends on the kind of dimensions.

\section{Noninventory-based variety-seeking models}

Most of these models are based on the concept of first-order Markov chains and attempt to predict switching probabilities from concepts of variety seeking. Givon (1984) proposed a first-order Markov model based on the assumption that a variety seeker evaluates change positively, regardless of the alternative previously chosen. His model assumes the probability of choosing alternative $i$ given that 
alternative $j$ was chosen at a previous occasion is a function of the preference for choice alternative $i$ and of preference for switching. Individuals may have a negative switching preference. Givon also extended this model to situations in which an individual partitions choice alternatives according to some underlying attribute and seeks variety by switching among partitions. In this case, the probability of choosing alternative $i$ given that alternative $j$ was chosen at the previous occasion is a function of preference for alternative $i$ and of preference for all alternatives in the same partition as alternative $j$. This model was further extended by McAlister (1984) and Lattin and McAlister (1985). Following Tversky's (1977) ideas on similarity, they assumed that similarity between choice alternatives is a function of the features they share.

None of these models can be used to predict the likely impacts of planning decisions on choice behaviour. Borgers et al. (1989) therefore developed a planning model which incorporated policy-relevant variables. The switching probabilities are made a function of a utility associated with variety-seeking behaviour and a matching function which defines the degree of (dis)similarity between the choice alternatives. They found that this model outperformed a conventional choice model in a study of recreational choice behaviour.

\section{Dynamic discrete choice models}

Recently, standard discrete choice theory as applied to static choice behaviour has been extended to dynamic choice behaviour. Seminal work in this area has been conducted by Heckman (1981), whose major concern was to distinguish between true state dependence and spurious state dependence resulting from serial correlation. He developed a general framework for analysing dynamic choice and showed how several models such as Bernoulli models, models with structural state dependence, renewal models, models with general correlations in the error term, and habit persistence models can be accommodated in his general model.

Another important publication stems from Tardiff (1979), who showed that under certain circumstances conventional discrete choice models can be applied directly to the dynamic problem and that in the case in which the error terms of the utility function are assumed to be correlated over time, standard estimation procedures are no longer valid. In this case one should either adopt a fixed effects approach in which the error terms are explicitly identified and standard discrete choice models are applied directly or a random effects approach in which the error variance structure is dealt with directly. Daganzo and Sheffi (1982) showed that the choice of a state dependence model, a serial correlation model or a hybrid there of is simply a specification issue, implying that existing computer codes can be used to estimate such models of dynamic choice behaviour. An application of their approach to two-period panel data can also be found in Johnson and Hensher (1982). Krishnan and Beckmann (1979) extended Krishnan's static logit 
model for binary choices which incorporates threshold effects to the case of dynamic choice behaviour. Another interesting development is the beta logistic model (Heckman and Willis, 1977). This model provides predictions for both the mean probability of choosing a particular alternative and the distribution of the choice probabilities around the mean. The original model is based on the assumptions that the exogenous variables are constant over time and the absence of state/time dependence. Heterogeneity is introduced by defining a subgroup of a sample in which all individuals have exactly the same values on all exogenous variables included in the model. The distribution of the probabilities for such a group represents heterogeneity. Given these assumptions the beta logistic model assumes that the mean probability can be modelled in terms of a conventional logit model, and that the distribution of probabilities is a beta distribution. The original specification of the dichotomous beta logistic model has been generalized by Davies (1984) and Davies and Pickles (1984) to incorporate feedback effects and time-varying exogenous variables. They applied the model successfully to the study of residential mobility. The dichotomous model may be extended to the polytomous case by replacing the binomial distribution of the logistic model by the multinomial distribution and the beta distribution describing heterogeneity by the Dirichlet distribution. In the UK, geographers Dunn and Wrigley (1985) provide an application of this model in a study of spatial shopping behaviour.

The field of dynamic discrete choice models is developing rapidly. Apart from the contributions discussed above, several other important publications have appeared recently. For example, Avery et al. (1983) presented a multiperiod probit model; Hensher (1984) developed a quasi-dynamic choice model for automobile demand; Meyer and Sathi (1985) have discussed a dynamic model of consumer choice involving product learning; Miller and O'Kelly (1983) used a dynamic logit model to predict shopping destination choice. Theoretical models of dynamic choice behaviour have been developed by Leonardi (1983), Deneubourg et al. (1979), De Palma and Lefvre (1981; 1983) and De Palma (1983).

\section{Discussion and summary}

The overview we have presented in this paper necessarily goes beyond the strict disciplinary boundaries of geography. Crossdisciplinary synthesis of concepts, theories, models and methods has become an ever-increasing component of academic research and the accumulation of knowledge. We have ventured beyond the 'bounds' of the discipline for a very simple reason. Much of the applied work that is behaviourally based and had its conceptual, theoretical or modelling origins within geography now finds many of its most vigorous applications outside our discipline. Thus, when critics argue that behavioural research has been little applied in our discipline, they miss the point on two accounts: 1) there is a substantial volume of applied behaviourally based work 
within our discipline in diverse areas of human geography; and 2) there has been substantial spillover into complementary academic and applied fields, and we feel this must be recognized as part of any evaluation of the contribution of spatial behavioural research.

We have argued that even much of the early behavioural research was applied in nature. Much of it was actually a mix of theoretical and applied work, while some focused largely on measurement and modelling problems that had to be solved before real-world applications could take place. This necessarily took time, and although it may have appeared to the eager consumer of behavioural literature that little forward progress was being made, the reverse was true. Before progressing, substantial problems had to be solved. These problems ran the gamut from philosophy to measurement and required interested researchers to both stick out their necks and stick to their guns in the face of waning support and increasing criticism.

We feel that applied research has developed to such an extent, and knowledge has accumulated to such an extent, that theory and practice are now so closely intertwined that each automatically bolsters the other, proceeding in a complex upward spiral of increased understanding, increased usefulness, increased relevance and increased explanatory and predictive power. Furthermore, we suggest that behaviourally based research has been growing at a rate much faster than the rate of growth of many other parts of geography; that behaviourally based knowledge has dramatically increased our understanding of the role and importance of space, spatial experience and spatial relations in everyday life; and that the sheer volume of interesting researchable problems for the behavioural researcher has substantially exceeded the capability of geographers to investigate them. If we do not direct more attention to such problems ourselves, continuous erosion is likely to occur as disciplines such as cognitive science, neurosciences, robotics, environmental psychology, planning, architecture and environmental design (to name but a few) take on spatially relevant behavioural problems. Evidence of the latter can be seen in the dramatic decrease in the relative importance of geographical contributions to national and international conferences of the Environmental Design and Research Association - in which the contribution of geographers to both theoretical or applied behaviourally based environmental research has been steadily diminishing over the years.

It must also be obvious to readers of this review that there are other components of behaviourally based research which have progressed equally as much as the ones we have chosen to document, but upon which we have not commented. To name but a few, the extensive work in time geography and the continued development of hazard perception research, represent two streams of applied research which appear to be having substantial implications for policy development in both advanced and emerging nations. Adequate documentation of research activity in these two areas would take another paper the size of this one, and we have left that for other more knowledgeable and more venturous researchers to pursue. 
The research we have documented in the two papers has produced few dead ends. Even little developed areas, such as the application of learning models in a spatial context, have not died out and indeed appear to be re-emerging. Notable success stories lie in the development and application of decision, choice and preference models in a variety of contexts, most noticeably the housing choice context. Similarly, environmental and cognitive mapping research has opened new ways for geographers to contribute to solving problems in our complex world. Geographic interest in the special problems of the retarded, the disabled, the blind and vision-impaired, the mentally disturbed, the homeless, the aged, and the worlds of children, has shown both our academic peers and the community at large that the geographer's peculiar knowledge of space and spatial relations has immediate and distinct societal value. The increased variety of problems investigated and solved by geographers using behavioural theory, models and methods is helping the discipline to establish its right to continue as a vibrant academic area. Many of the problem areas we have reviewed remain only superficially analysed and the potential for future geographic research in these areas is virtually unbounded.

University of Technology, Eindhoven, The Netherlands

University of California at Santa Barbara, USA

\section{References}

Adiv, A. 1983: The structure of the work-trip based on analysis of trip diaries in the San Francisco Bay area. In Carpenter, S. and Jones, P., editors, Recent advances in travel demand analysis, Aldershot: Gower, 117-36.

Adler, T. and Ben-Akiva, M. 1979: A theoretical and empirical model of trip chaining behavior. Transportation Research B 13, 136-50.

Anas, A. 1982: Residential location markets and urban transportation: economic theory, econometrics and policy analysis with discrete choice models. New York: Academic Press.

1983: Discrete choice theory, information theory and the multinomial logit and gravity models. Transportation Research B 17, 13-23.

1984: Discrete choice theory and the general equilibrium of employment, housing and travel networks in a Lowry-type model of urban economy. Environment and Planning A 16,1489-502.

Anderson, N. 1974: Information integration theory: a survey. In Krantz, D., Atkinson, R. and Luce, R., editors, Contemporary developments in mathematical psychology, San Francisco: W.H. Freeman, 236-301.

Avery, R., Hansen, L. and Hotz, V. 1983: Multiperiod probit models and orthogonality condition estimation. International Economic Review 24, 21-35.

Batsell, R. 1981: A multiattribute extension of the Luce model which simultaneously scales utility and substitutability. Working Paper from a Conference at Quail Roost. 
Bettman, J. 1970: Information processing models of consumer behaviour. Journal of Marketing Research 7, 370-76.

Borgers, A., Van der Heijden, R. and Timmermans, H. 1989: A variety seeking model of spatial choice behaviour. Environment and Planning $A$, forthcoming.

Borgers, A. and Timmermans, H. 1986a: A model of pedestrian route choice and demand for retail facilities within inner-city shopping areas. Geographical Analysis $28,115-28$.

1986b: City centre entry points, store locations patterns and pedestrian route choice behaviour: a micro-level simulation model. Socio-Economic Planning Sciences 20, 25-31.

1988: A context-sensitive model of spatial choice behaviour. In Golledge, R. and Timmermans, H., editors, Behavioural modelling in geography and planning, London: Croom Helm, 159-78.

Broom, D. and Wrigiey, N. 1983: Incorporating explanatory variables into stochastic panel-data models of urban shopping behaviour. Urban Geography 4, 244-57.

Burnett, P. 1974: A three state Markov model of choice behaviour within spatial structures. Geographical Analysis 6, 53-68.

1975: A Bernoulli model of destination choice. Transportation Research Record 527, 33-44.

1977: Tests of a linear learning model of destination choice: applications to shopping travel by heterogeneous groups. Geografiska Annaler B 59, 95-108.

1978: Markovian models of movement within urban spatial structures. Geographical Analysis 110, 142-53.

Cattin, P., Gelfland, A. and Danes, J. 1983: A simple Bayesian procedure for estimation in a conjoint model. Journal of Marketing Research 20, 29-36.

Chatfield, C., Ehrenberg, A. and Goodhardt, G. 1966: Progress on a simplified model of stationary purchasing behaviour. Journal of the Royal Statistical Society A 129, $317-67$.

Clark, W. and Smith, T. 1985: Production system models of residential search behaviour: a comparison of computer-simulated and real-world environments. Environment and Planning A 17, 555-68.

Cohen, J., Fishbein, M. and Ahtola, O. 1972: The nature and uses of expectancy-value models in consumer attitude research. Journal of Marketing Research 9, 456-60.

Coombs, C. 1964: A theory of data. New York: John Wiley \& Sons.

Cooper, L. and Nakanishi, M. 1983: Standardizing variables in multiplicative choice models. Journal of Consumer Research 10, 96-108.

Crouchley, R., Pickles, A. and Davies, R. 1982: Dynamic models of shopping behaviour: testing the linear learning model and some alternatives. Geografiska Annaler B 63, 27-33.

Daganzo, C.F. 1979: Multinomial probit: the theory and its application to demand forecasting. New York: Academic Press.

Daganzo, C. and Sheffi, Y. 1982: Multinomial probit with time series data: unifying state dependence and serial correlation models. Environment and Planning $A 14$, $1377-88$.

Damm, D. 1982: Parameters of activity behaviour for use in travel analysis. Transportation Research A 16, 135-48.

Davies, R. 1984: A generalized beta-logistic model for longitudinal data. Environment and Planning $A$ 16, 1375-86. 
Davies, R. and Pickles, A. 1984: Accounting for omitted variables in the analysis of panel and other longitudinal data. Papers in Planning Research 77, University of Wales, Institute of Science and Technology, Cardiff.

De Palma, A. 1983: Incomplete information, expectation, and subsequent decision making. Environment and Planning A 15, 123-30.

De Palma, A. and Lefevre, C. 1981: A probabilistic search model. Journal of Mathematical Sociology 8, 43-60.

1983: Individual decision making in dynamic collective systems. Journal of Mathematical Sociology 9, 103-24.

Deneubourg, J., De Palma, A. and Kahn, D. 1979: Dynamic models of competition between transportation modes. Environment and Planning 11,665-73.

Desbarats, I. 1983: Spatial choice and constraints on behaviour. Annals of the Association of American Geographers 73, 340-57.

Dieleman, F. 1983: Tenure and allocation policy in the Tilburg housing market. Tijdschrift voor Economishe en Sociale Geografie 74, 162-74.

Dunn, R., Longley, P. and Wrigley, N. 1984: Logit models of urban tenure choice: graphical methods for determining functional form. Paper presented at the Symposium of the IGU Working Group on Systems Analysis and Mathematical Models, Besanon.

Dunn, R., Reader, S. and Wrigley, N. 1983: An investigation of the assumptions of the NBD model as applied to purchasing at individual stores. Applied Statistics 32 , 249-59.

Dunn, R. and Wrigley, N. 1985: Beta-logistic models of urban shopping center choice. Geogfraphical Analysis 17, 95-113.

Eagle, T. 1984: Parameter stability in disaggregate retail choice models: experimental evidence. Journal of Retailing 60, 101-23.

1988: Context effects in consumer spatial behaviour. In Golledge, R. and Timmermans, H., editors, Behavioural modelling in geography and planning, London: Croom Helm, 299-324.

Ehrenberg, A. 1968: The practical meaning and usefulness of the NBD/LSD theory of repeat buying. Applied Statistics 17, 17-32.

1972: Repeat buying: theory and application. Amsterdam: North Holland Publishing Company.

Einhorn, H. 1970: The use of nonlinear, noncompensatory models in decision making. Psychological Bulletin 73, 221-30.

1971: Use of nonlinear noncompensatory models as a function of task and amount of information, organizational behaviour and human performance. Psychological Bulletin 6, 1-27.

Einhorn, H. and Gonedes, N. 1971: An exponential discrepancy model for attitude evaluation. Behavioural Science 16, 152-57.

Farquhar, P. and Rao, V. 1976: A balance model of evaluating subsets of multiattribute items. Management Science 22, 528-39.

Fischer, M. and Aufhauser, E. 1988: Housing choice in a regulated market: a nested multinomial logit analysis. Geographical Analysis 20, 47-69.

Fischer, M. and Maier, G. 1984: Spatial discrete choice and labour supply modelling: some alternative probability choice structures. Paper presented at the Meeting of the IGU Working Group on Systems Analysis and Mathematical Models, Besancon. 
Fishbein, M. 1967: Attitudes and prediction of behaviour. In Fishbein, M., editor, Readings in attitude theory and measurements, New York: John Wiley \& Sons, 477-92.

Foerster, J. 1979: Mode choice decision process models: a comparison of compensatory and noncompensatory structures. Transportation Research $B$ 13, 17-28.

Fotheringham, A. 1983a: A new set of spatial interaction models: the theory of competing destinations. Environment and Planning A 15, 15-36.

1983b: Some theoretical aspects of destination choice and their relevance to production-constrained gravity models. Environment and Planning A 15, 1121-32. 1984: Spatial structure and the parameters of spatial interaction models. Geographical Analysis 12, 33-46.

1985: Spatial competition and agglomeration in urban modelling. Environment and Planning A 17, 213-30.

Gaudry, M. and Dagenais, M. 1979: The dogit model. Transportation Research B 13, $105-11$.

Gensch, D. and Svenstka, J. 1979: An exact heirarchical algorithm for determining aggregate statistics from individual choice data. Management Science 25, 939-52.

Gilbert, G., Peterson, G. and Schofer, J. 1972: Markov renewal model of linked trip travel behaviour. Transportation Engineering Journal 3, 691-704.

Givon, M. 1984: Variety seeking through brand switching. Marketing Science 3, 1-22.

Golledge, R. 1970: Some equilibrium models of consumer behaviour. Economic Geography Supplement 46, 417-24.

Golob, T. 1984: A descriptive analysis of trip-chaining behaviour in the Netherlands. Proceedings, Seminar H, PTRC Summer Annual Meeting, PTRC Education and Research Service, London.

1986: A non-linear canonical correlation analysis of weekly trip chaining behaviour in the Netherlands. Transportation Research A 20, 385-99.

Goodhardt, G., Ehrenberg, A. and Chatfield, C. 1984: The Dirichlet: a comprehensive model of buying behaviour. Journal of the Royal Statistical Society A 147, 621-55.

Green, P., Goldberg, S. and Montemayor, M. 1981: A hybrid utility estimation model for conjoint analysis. Journal of Marketing 45, 33-41.

Halperin, W. 1985: The analysis of panel data for discrete choices. In Nijkamp, P., Leitner, H. and Wrigley, N., editors, Measuring the unmeasurable, The Hague: Martinus Nijhoff Publishers, 561-86.

Halperin, W. and Gale, N. 1984: Towards behavioural models of spatial choice: some recent developments. In Pitfield, D., editor, Discrete choice models in regional science, London: Pion, 9-28.

Hanson, S. 1979: Urban-travel linkages: a review. In Henscher, D. and Stopher, P., editors, Behavioural travel modelling, London: Croom Helm, 81-100.

1980: Spatial diversification and multi-purpose travel: implications for choice theory. Geographical Analysis 12, 245-57.

Hanson, S. and Hanson, P. 1981: The travel activity patterns of urban residents: dimensions and relationships to socio-demographic characteristics. Economic Geography 57, 332-47.

Hauser, J. and Tversky, A. 1981: Agendas and choice probabilities. Working Paper from a Conference at Quail Roost.

Hausman, J. and Wise, D. 1978: A conditional probit model for qualitative choice: discrete decisions recognizing interdependence and heterogeneous preferences. 
Econometrica 46, 403-26.

Heckman, J. 1981: Statistical models for discrete panel data. In Manski, C. and McFadden, D., editors, Structural analysis of discrete data with econometric applications, Cambridge, MA: MIT Press, 114-78.

Heckman, J. and Willis, R. 1977: A beta-logistic model for the analysis of sequential labor force participation by married women. Journal of Political Economy 85, $27-58$.

Hendriks, P. 1985: Measurement of attractiveness of places of study. Tijdschrift voor Economische en Sociale Geografie 76, 22-31.

Hensher, D. 1983: A sequential attribute dominance model of probabilistic choice. Transportation Research A 17, 215-18.

1984: Model specification for quasi-dynamic discrete-continuous choice automobile demand system in discrete time using panel data. Working Paper No. 11, School of Economic and Financial Studies, Macquarie University, North Ryde, Australia.

Hensher, D. and Louviere, J. 1979: Behavioural intentions as predictors of very specific behaviour. Transportation 8, 167-72.

Hensher, D. and Wrigley, N. 1984: Statistical modelling of discrete choices with panel data. Working Paper No. 16, Dimensions of Automobile Demand Project, School of Economic and Financial Studies, Macquarie University, North Ryde, Australia.

Herniter, J. 1971: A probabilistic market model of purchase timing and brand selection. Management Science 18, 102-13.

Horowitz, J. 1979: Disaggregate demand model for nonwork travel. Transportation Research Record 673, 65-71.

1980: A utility maximizing model of the demand for multidestination non-work travel. Transportation Research B 14, 369-86.

Horton, F. and Schuldiner, P. 1967: The analysis of land use linkages. Highway Research Record 165, 96-107.

Huber, G. 1974: Multiattribute utility models: a review of field and field-like studies. Management Science 20, 1393-402.

Huber, G., Daneshgar, R. and Ford, D. 1971: An empirical comparison of five utility models for predicting job preferences. Organizational Behaviour and Human Performance 6, 167-282.

Huber, G., Sahney, V. and Ford, D. 1969: A study of subjective evaluation models. Behavioural Science 14, 483-89.

Huber, J. 1982: The effect of set composition on item choice: separating attraction, edge aversion and substitution effects. Working Paper, Duke University.

Huher, J., Payne, J. and Puto, C. 1982: Adding asymmetrically dominated alternatives: violations of regularity and the similarity hypothesis. Journal of Consumer Research 9, 90-98.

Huber, J. and Puto, C. 1983: Market boundaries and product choice: illustrating attraction and substitution effects. Journal of Consumer Research 10, 31-44.

Huber, J. and Sewall, M. 1982: The effect of item similarity on aggregate choice: modelling dominance and substitution effects, Working Paper, Duke University.

Huigen, P. 1983: Access and settlement pattern in peripheral rural areas. Paper presented at a Dutch-Hungarian Workshop on Consequences of the Rural Developments in the Netherlands and Hungary, Utrecht.

Jeuland, A., Bass, F. and Wright, G. 1980: A multibrand stochastic model compounding heterogenous Erland timing and multinomial choice processes. 
Operations Research 28, 255-77.

Johnson, E. and Meyer, R. 1984: Compensatory choice models of noncompensatory processes: the effect of varying context. Journal of Consumer Research 11, 528-41.

Johnson, E. and Payne, J. 1985: Effort and accuracy in choice. Management Science $31,395-414$.

Johnson, L. and Hensher, D. 1982: Application of multinomial probit to a two-period panel data set. Transportation Research A 16, 457-64.

Jones, J. and Zufryden, F. 1980: Adding explanatory variables to a consumer purchase behaviour model: an exploratory study. Journal of Marketing Research 17, 323-34. 1982: An approach for assessing demographic and price influences on brand purchase behaviour. Journal of Marketing 46, 36-46.

Kamakura, W. and Srivastava, R. 1984: Predicting choice shares under conditions of brand interdependence. Journal of Marketing Research 21, 420-34.

Kau, K. and Ehrenberg, A. 1984: Patterns of store choice. Journal of Marketing Research 21, 399-409.

Kitamura, R. 1983: A sequential, history dependent approach to trip chaining behaviour. Transportation Research Record 944, 13-22.

1984a: Incorporating trip chaining into analysis of destination choice. Transportation Research $B$ 18, 67-82.

1984b: A model of daily time allocation to discretionary out-of-home activities and trips. Transportation Research B 18, 255-66.

Kitamura, R. and Kermanshah, M. 1983: Identifying time and history dependencies of activity choice. Transportation Research Record 944, 22-30.

1984: A sequential model of interdependent activity and destination choice. Transportation Research Record 987, 81-89.

Kitamura, R. and Lam, T. 1983: A time-dependent Markov renewal model of trip chaining. In Hardle, V., Hauer, E. and Steuart, G., editors, Proceedings of the Eighth International Symposium on Transportation and Traffic Theory, Toronto: University of Toronto Press, 376-402.

Knight, R. and Menchik, M. 1976: Conjoint preference estimation for residential policy land use evaluation. In Golledge, R. and Rushton, G., editors, Spatial choice and spatial behaviour, Columbus, $\mathrm{OH}$ : Ohio State University Press, 135-56.

Kondo, K. and Kitamura, R. 1987: Time space constraints and the formation of trip chains. Regional Science and Urban Economics 17, 49-65.

Koppelman, F. and Pas, E. 1985: Travel activity behaviour in time and space: methods for representation and analysis. In Nijkamp, P., Leitner, H. and Wrigley, N., editors, Measuring the unmeasurable, The Hague: Martinus Nijhoff, 587-628.

Krishnan, K. 1977: Incorporating thresholds of indifference in probabilistic choice models. Management Science 23, 1224-33.

Krishnan, K. and Beckmann, M. 1979: Dynamic disaggregate choice models with an application in transportation. Decision Sciences 10, 218-31.

Lattin, J. and McAlister, L. 1985: Using a variety seeking model to identify substitute and complementary relationships among competing products. Journal of Marketing Research 22, 330-39.

Lenntorp, B. 1976: Paths in time-space environments: a time-geographic study of movement possibilities of individuals. Lund Series in Geography, Series B, Human Geography No. 44, University of Lund, Sweden.

Leonardi, G. 1983: An optimal control representation of a stochastic multistage 
multiactor choice process. In Griffith, D. and Lea, A., editors, Evolving geographical structures: mathematical models and theories for space-time processes, The Hague: Martinus Nijhoff, 62 73 .

Lerman, S. and Liu, T. 1984: Microlevel econometric analysis of retail closure. In Pitfield, D., editor, Discrete choice models in regional science, London: Pion, 181-201.

Lieber, S. 1979: An experimental approach to the migration decision process. Tijdschrift voor Economische en Sociale Geografie 70, 75-85.

Lieber, S. and Fesenmaier, D. 1984: Modelling recreational choice: a case study of management alternatives in Chicago. Regional Studies 18, 31-43.

Lioukas, S. 1984: Thresholds and transitivity in stochastic consumer choice: a multinomial logit analysis. Management Science 30, 110-22.

Longley, P. 1984: Comparing discrete choice models: some housing market examples. In Pitfield, D., editor, Discrete choice models in regional science, London: Pion, $163-81$.

Longley, P. and Wrigley, N. 1984: Scaling residential preferences: a methodological note. Tijdschrift voor Economische en Sociale Geografie 75, 292-99.

Louviere, J. 1979: Modelling individual residential preferences: a totally disaggregate approach. Transportation Research B 4, 1-15.

1984a: Hierarchical information integration: a new method for the design and analysis of complex multiattribute judgment problems. In Kinnear, T., editor, Advances in consumer research Volume xi, Provo, UT: Association for Consumer Research, 148-55.

1984b: Using discrete choice experiments and multinomial logit choice models to forecast trial in a competitive retail environment: a fast food restaurant illustration. Journal of Retailing 60, 81-107.

1985: Conjoint judgment and choice models that allow correlated attributes without sacrificing orthogonal parameter estimation. Unpublished manuscript.

Louviere, J. and Gaeth, G. 1987: Decomposing the determinants of retail facility choice using the method of hierarchical information integration: a supermarket illustration. Journal of Retailing 63, 25-48.

Louviere, J. and Henley, D. 1977: Information integration theory applied to student apartment selection decisions. Geographical Analysis 9, 130-41.

Louviere, J. and Hensher, D. 1982: Design and analysis of simulated choices or allocation experiments in travel choice modeling. Transportation Research Record 890, 11-17.

Louviere, J, and Kocur, G. 1983b: The magnitude of individual-level variations in demand coefficients: a Xenia, Ohio case example. Transportation Research $A 17$, 363-74.

Louviere, J. and Meyer, R. 1976: A model for residential impression formation. Geographical Analysis 8, 479-86.

1979: Behavioural analysis of destination choice. Technical Report 112, University of Iowa.

1981: A composite attitude behavioural model of traveller decision making. Transportation Research B 15, 411-20.

Louviere, J. and Timmermans, H. 1987: A review of some recent advances in decompositional preference and choice models. Paper presented at the Fifth European Colloquium on Quantitative and Theoretical Geography, Bardonecchia, Italy. 
1989: Hierarchical information integration applied to recreation destination choice. (Forthcoming.)

Louviere, J. and Wilson, E. 1978: Predicting consumer response in travel analysis. Transportation Planning and Technology 4, 1-19.

Louviere, J. and Woodworth, G. 1983: Design and analysis of simulated consumer choice and allocation experiments: an approach based on aggregate data. Journal of Marketing Research 10, 350-67.

Luce, R. 1959: Individual choice behaviour. New York: John Wiley \& Sons.

1977: The choice axiom after twenty years. Journal of Mathematical Psychology 15, 215-33.

McAlister, L. 1979: Choosing multiple items from a product class. Journal of Consumer Research 6, 213-24.

1982: A dynamic attribute satiation model of variety seeking behaviour. Journal of Consumer Research 9, 141-51.

1984: A similarity based Markov model of variety seeking behaviour: its implications and a linear programming technique to estimate its parameters, MIT Working Paper 1593-84, A. P. Sloan School of Management, Cambridge, MA.

McAlister, L. and Pessemier, E. 1982: Variety-seeking behaviour: an interdisciplinary review. Journal of Consumer Research 9, 311-22.

McFadden, D. 1978: Modelling the choice of residential location. In Karlquist, A. et al., editors, Spatial interaction theory and planning models, Amsterdam: North Holland, 75-96.

Manski, C. and Lerman, S. 1977: The estimation of choice probabilities from choice based samples. Econometrica $45,1977-88$.

Marble, D. 1964: A simple Markovian model of trip structures in a metropolitan region. Papers of the Regional Science Association, 150-56.

Meyer, R. and Eagle, T. 1981: A parsimonious multinomial choice model recognizing alternative interdependence and context-dependent utility functions. Working Paper 26-80-81. Graduate School of Industrial Administration, Carnegie Mellon University, Pittsburg.

1982: Context-induced parameter instability in a disaggregate stochastic model of store choice. Journal of Marketing Research 19, 62-71.

Meyer, R. and Sathi, A. 1985: A multiattribute model of consumer choice during product learning. Marketing Science 4, 41-61.

Miller, E. and Lerman, S. 1981: Disaggregate modelling and decisions of retail firms: a case study of clothing retailers. Environment and Planning A 13, 729-46.

Miller, E. and O'Kelly, M. 1983: Estimating shopping destination models from travel diary data. The Professional Geographer 35, 440-49.

Miller, G., Galanter, A. and Pribam, K. 1960: Plans and the structure of behaviour. New York: Holt, Rinehart \& Winston.

Montgomery, H. and Svenson, O. 1976: On decision rules and information processing strategies for choices among multiattribute alternatives. Scandinavian Journal of Psychology 17, 283-91.

Nishii, K. and Sasaki, T. 1986: An analysis of travel pattern and modal split in a business trip chaining. Paper Presented at the World Conference on Transport Research, Vancouver.

O'Brien, L. and Wrigley, N. 1984: A generalized linear model approach to categorical data analysis: theory and applications in geography and regional science. In. 
Bahrenberg, G., Fischer, M. and Nijkamp, P., editors, Recent developments in spatial data analysis: methodology, measurement, models, Gower: Aldershot, 231-52.

O'Kelly, M. 1981: A model of the demand for retail facilities incorporating multistop, multipurpose trips. Geographical Analysis 13, 134-48.

O'Kelly, M. and Miller, E. 1984: Characteristics of multistop multipurpose travel: an empirical study of trip length. Transportation Research Record 976, 33-39.

Op't Veld, A., Timmermans, H. and Starmans, J. 1987: Decision nets and housing choice processes. Paper presented at the Fifth European Colloquium on Quantitative and Theoretical Geography, Bardonecchia, Italy.

Onaka, J. 1983: A multiple-attribute housing disequilibrium model of residential mobility. Environment and Planning $A$ 15, 751-65.

Onaka, J. and Clark, W. 1983: A disaggregate model of residential mobility and housing choice. Geographical Analysis 15, 287-304.

Ortuzar, J. 1983: Nesting logit models for mixed-mode travel in urban corridors. Transportation Research A 17, 283-99.

Oster, C. 1979: The second role of the work trip: visiting non-work destination. Transportation Research Record 728, 79-81.

Park, C., Hughes, R., Thurkal, V. and Friedman, R. 1981: Consumer decision plans and subsequent choice behaviour. Journal of Marketing 45, 33-47.

Paull, A. 1978: A generalized compound Poisson model for consumer purchase panel data analysis. Journal of the American Statistical Association 73, 706-13.

Pessemier, E. 1985: Varied individual behaviour: some theories, measurement and models. Multivariate Behavioural Research 20, 69-94.

Peterson, G., Dwyer, J. and Darragh, A. 1983: A behavioural urban site choice model. Leisure Sciences 6, 61-81.

Phipps, A. and Laverty, W. 1983: Optimal shopping and residential search behaviour. Geographical Analysis 15, 187-204.

Phipps, A. and Meyer, R. 1985: Normative versus heuristic models of residential search behaviour: an empirical comparison. Environment and Planning $A$ 17, 761-76.

Recker, W. and Golob, T. 1979: A noncompensatory model of transportation behaviour based on a sequential consideration of attributes. Economic Geography 57 , 373-83.

Recker, W., McNally, M. and Root, G. 1986a: A model of complex travel behaviour: part I: theoretical development. Transportation Research A 20, 307-18.

1986b: A model of complex travel behaviour: part II: an operational model. Transportation Research A 20, 319-30.

Recker, W. and Schuler, H. 1981: Destination choice and processing spatial information: some empirical tests with alternative constructs. Economic Geography 57, 373-83.

Root, G. and Recker, W. 1983: Towards a dynamic model of individual activity pattern formation. In Carpenter, S, and Jones, P., editors, Recent advances in travel demand analysis, Aldershot: Gower.

Rosenberg, M. 1956: Cognitive structure and attitudinal effect, Journal of Abnormal and Social Psychology 53, 367-72.

Scholten, H. 1984: Residential mobility and loglinear modelling. In Bahrenberg, G., 
Fischer, M. and Nijkamp, P., editors, Recent developments in spatial data analysis: methodology, measurement, models, Aldershot: Gower, 271-88.

Scholten, H. and Hooimeyer, P. 1984: The use of vacancy chains and loglinear models to analyze relationships among housing submarkets. Tijdschrift voor Economische en Sociale Geografie 75, 202-13.

Smith, T.E. and Yu, W. 1982: A prominence theory of context-sensitive choice behaviour. Journal of Mathematical Sociology 8, 225-49.

Smith, T.R. 1983: Computational process models of individual decision making behaviour. In Crosby, R., editor, Cities and regions as non-linear decision systems, Colorado: Westview Press, 175-210.

Smith, T.R., Clark, W. and Cotton, J. 1984: Deriving and testing production system models of sequential decision-making behaviour. Geographical Analysis 16, 191-222.

Smith, T.R. and Lundberg, C. 1984: Psychological foundations of individual choice behaviour and a new class of decision making models. In Bahrenberg, G., Fischer, M. and Nijkamp, P., editors, "Recent developments in spatial data analysis: methodology, measurement, models, Aldershot: Gower, 355-74.

Smith, T.R., Pellegrino, J. and Golledge, R. 1982: Computational process modelling of spatial cognition and behaviour. Geographical Analysis 14, 305-25.

Smith, T.R. and Slater, P. 1981: A family of spatial interaction models incorporating information flows and choice set constraints applied to U.S. interstate labor flows. International Regional Science Review 6, 15-31.

Southworth, F, 1981: Calibration of multinomial logit models of mode and destination choice. Transportation Research A 15, 315-25.

Strauss, D. 1981: Choice by features: an extension of Luce's choice model to account for similarities. British Journal of Mathematical and Statistical Psychology 34, $50-61$.

Svenson, O. 1979: Process descriptions of decision making. Organizational Behaviour and Human Performance 23, 86-112.

Swiderski, D. 1983: A model for simulating spatially and temporally coordinated activity sequences on the basis of mental maps. In Carpenter, S. and Jones, P., editors, Recent advances in travel demand analysis, Aldershot: Gower, 313-34.

Swinth, R. 1976: A decision process model for predicting job preferences. Journal of Applied Psychology 61, 242-45.

Tardiff, T. 1979: Definition of alternatives and representation of dynamic behavior in spatial choice models. Transportation Research Record 723, 25-30.

Thurstone, L. 1927: A law of comparative judgment. Psychological Review 34, 273-86.

Timmermans, H. 1980a: Unidimensional conjoint measurement models and consumer decision-making. Area 12, 291-300.

1980b: Consumer spatial choice strategies: a comparative study of some alternative behavioural spatial shopping models. Geoforum 11, 123-31.

1982: Consumer choice of shopping center: an information integration approach. Regional Studies 16, 171-82.

1983: Noncompensatory decision rules and consumer spatial choice behaviour: a test of predictive ability. The Professional Geographer 35, 449-85.

1984a: Decompositional multiattribute preference models in spatial choice analysis: a review of some recent developments. Progress in Human Geography 8, 189-221. 
1984b: Decision models for predicting preferences among multiattribute choice alternatives. In Bahrenberg, G., Fischer, M. and Nijkamp, P., editors, Recent developments in spatial data analysis: methodology, measurement, models, Aldershot: Gower, 337-54.

1984c: Discrete choice models versus decompositional multiattribute preference models: a comparative analysis of model performance in the context of spatial shopping behaviour. In Pitfield, D., editor, Discrete choice models in regional science, London: Pion, 88-102.

1985: Variety seeking models and recreational choice behaviour. Paper presented at the Pacific Regional Science Conference, Molokai, Hawaii.

1988: Hierarchical information integration applied to residential choice processes. Paper presented at the Annual Meeting of the Association of American Geographers, Phoenix, Arizona.

Timmermans, H. and Borgers, A. 1985: Choice set constraints and spatial decisionmaking processes. Sistemi Urbani 3, 211-20.

1989:

Timmermans, H. and Van der Heijden, R. 1984: The predictive ability of alternative decision rules in decompositional multiattribute preference models. Sistemi Urbani 5, 89-101.

1987: Uncovering spatial decision-making processes: a decision net approach applied to recreational choice behaviour. Tijdschrift voor Economische en Sociale Geografie 78, 297-304.

Timmermans, H., Van der Heijden, R. and Westerveld, H. 1984: Decision-making between multiattribute choice alternatives: a model of spatial shopping behaviour using conjoint measurements. Environment and Planning $A$ 16, 377--87.

Tversky, A. 1972a: Elimination-by-aspects: a theory of choice. Psychological Review 79, 281-99.

1972b: Choice by elimination. Journal of Mathematical Psychology 9, 341-67.

1977: Features of similarity. Psychological Review 84, 327--52.

Tversky, A. and Sattath, S. 1979: Preference trees. Psychological Review 86, 542-73.

Van der Hoorn, T. 1983a: Development of an activity model using a one-week activity diary data base. In Carpenter, S. and Jones, P., editors, Recent advances in travel demand analysis, Aldershot: Gower, 335-49.

1983b: Experiments with an activity-based travel model. Transportation 12, 61-77.

Van Lierop, W. 1981: Towards a new disaggregate model for the housing market. Research Memorandum 1981-1, Department of Economics, Free University, Amsterdam.

1985: Spatial interaction modelling and residential choice analysis. $\mathrm{PhD}$ dissertation, University of Amsterdam.

Van Lierop, W. and Nijkamp, P. 1984: Perspectives of disaggregate choice models in the housing market. In Pitfield, D., editor, Discrete choice models in regional science, London: Pion, 141-63.

Van Lierop, W. and Rima, A. 1985: Trends and prospects of qualitative disaggregate spatial choice models. In Nijkamp, P., Leitner, H. and Wrigley, N,, editors, Measuring the unmeasurable: the analysis of qualitative spatial data, The Hague: Martinus Nijhoff, 393-408.

Veldhuisen, J. 1984: An application of a linear logit regression model to residential mobility. In Bahrenberg, G., Fischer, M. and Nijkamp, P., editors, Recent 
developments in spatial data analysis: methodology, measurement, models, Aldershot: Gower, 289-303.

1985: The use of biproportional fitting and logit models to estimate the demand for different dwellings by populations of small areas. In Bahrenberg, G. and Deiters, J., editors, Methodology, models and methods in regional science, OSGMaterialien Nr. 5, Osnabruck.

Veldhuisen, J. and Timmermans, H. 1984: Specification of individual residential utility functions: a comparative analysis of three measurement procedures. Environment and Planning $A 16,1573-82$.

Westelius, O. 1973: The individual's way of choosing between alternative outlets. Stockholm: Svensk Byggtjanst.

Wheeler, J. 1972: Trip purpose and urban activity linkages. Annals of the Association of American Geographers 62, 641-54.

Willekens, F. 1983: Specification and calibration of spatial interaction models: a contingency-table perspective and an application to intra-urban migration in Rotterdam. Tijdschrift voor Economische en Sociale Geografie 74, $239-52$.

Willekens, F. and Shah, M. 1984: A note on loglinear modelling of rates and proportions. In Bahrenberg, G., Fischer, M. and Nijkamp, P., editors, Recent developments in spatial data analysis: methodology, measurement, models, Aldershot: Gower, 253-71.

Wilson, A. 1974: Urban and regional models in geography and planning. London: John Wiley \& Sons.

Wrigley, N. 1980: An approach to the modelling of shop-choice patterns: an explanatory analysis of purchasing patterns in a British city. In Herbert, D. and Johnston, R., editors, Geography and the urban environment: progress in research and applications, Chichester, Sussex: John Wiley \& Sons, 45-87.

1985: Categorical data analysis for geographers and environmental scientists. London: Longman.

Wrigley, N. and Dunn, R. 1984a: Diagnostics and resistant fits in logit choice models. In Pitfield, D., editor, Discrete choice models in regional science, London: Pion, 44-67.

1984b: Stochastic panel-data models of urban shopping behaviour: 1. purchasing at individual stores in a city. Environment and Planning $A 16,629-50$.

1984c: Stochastic panel data models of urban shopping behaviour: 2 . multi-store purchasing and the Dirichlet model. Environment and Planning $A$ 16, 759-78.

1984d: Stochastic panel-data models of urban shopping behaviour: 3 . the interaction of store choice and brand choice. Environment and Planning A 16, 1221-36.

1985: Stochastic panel-data models of urban shopping behaviour: 4 . incorporating independent variables into the NBD and Dirichlet models. Environment and Planning A 17, 319-32.

Young, W. 1984: A non-trade-off decision-making model of residential location choice. Transportation Research A 18, 1-12.

Young, W. and Brown, H. 1983: A revealed importance elimination-by-aspects model of mode choice. Paper presented at the PTRC Summer Conference, Sussex.

Young, W. and Ogden, K. 1983: Analysis of freight-facility location choice using an elimination-by-aspects model. Paper presented at the Australian Transportation Research Conference, Canberra.

Young, W., Richardson, A., Ogden, K. and Rattray, A. 1982: Road and rail freight 
354 Applications of behavioural research on spatial problems II

mode choice: the application of an elimination-by-aspects model. Transportation Research Record 838, 38-44.

Yu, W. 1978: Contributions to applications of linear logit models in transportation research. PhD Dissertation, University of Pennsylvania, Philadelphia, PA.

Zufryden, F. 1977: A composite heterogeneous model of brand choice and purchase timing behaviour. Management Science 24, 121-36.

1978: An empirical evaluation of a composite heterogeneous model of brand choice and purchase timing behaviour. Management Science 24, 761-73. 